\title{
1 Phylogenetic relationships of Rhizoctonia fungi within the Cantharellales
}

3 Dolores Gónzalez ${ }^{\mathrm{a},{ }^{*}}$, Marianela Rodriguez-Carres ${ }^{\mathrm{b}}$, Teun Boekhout ${ }^{\mathrm{c}}$, Joost Stalpers ${ }^{\mathrm{c}}$, Eiko E.

4 Kuramae $^{\mathrm{d}}$, Andreia K. Nakatani ${ }^{\mathrm{e}}$, Rytas Vilgalys ${ }^{\mathrm{f}}$, and Marc A. Cubeta ${ }^{\mathrm{b}}$

7 anstituto de Ecología, A.C., Red de Biodiversidad y Sistemática, Carretera Antigua a Coatepec

8 No. 351, El Haya, Xalapa, Veracruz, México. 91070

$9{ }^{\mathrm{b}}$ Department of Plant Pathology, North Carolina State University, Center For Integrated Fungal

10 Research, Campus Box 7251, Raleigh, NC 27695, USA.

$11{ }^{\mathrm{c}}$ CBS Fungal Biodiversity Centre, Uppsalalaan 8, 3584 CT Utrecht, The Netherlands.

$12{ }^{\mathrm{d}}$ Department of Microbial Ecology, Netherlands Institute of Ecology (NIOO/KNAW),

13 Droevendaalsesteeg 10, 6708 PB Wageningen, The Netherlands.

14 e UNESP, Faculdade de Ciências Agronômicas, CP 237,18603-970 Botucatu, SP, Brazil.

15 f Department of Biology, Duke University, Durham, NC 27708 USA.

16

20 *Corresponding author, Dolores González, Instituto de Ecología, A.C., Red de Biodiversidad y

21 Sistemática, Carretera Antigua a Coatepec No. 351, El Haya, Xalapa, Veracruz, México. 91070,

22 Phone +52 228 842-1800; Fax +52 228 818-7809. E-mail address: dolores.gonzalez@inecol.mx 


\section{Abstract}

25 Phylogenetic relationships of Rhizoctonia fungi within the order Cantharellales were studied 26 using sequence data from portions of the ribosomal DNA cluster regions ITS-LSU, rpb2, tefl

27 and atp6 for 50 taxa, and public sequence data from the rpb2 locus for 165 taxa. Data sets were 28 analyzed individually and combined using Maximum Parsimony, Maximum Likelihood and

29 Bayesian Phylogenetic Inference methods. All analyses supported the monophyly of the family

30 Ceratobasidiaceae, which comprises the genera Ceratobasidium and Thanatephorus. Multi-locus

31 analysis revealed 10 well supported monophyletic groups that were consistent with previous

32 separation into anastomosis groups based on hyphal fusion criteria. This analysis coupled with

33 analyses of a larger sample of $165 \mathrm{rpb} 2$ sequences of fungi in the Cantharellales supported a

34 sister relationship between the Botryobasidiaceae and Ceratobasidiaceae and a sister relationship

35 of the Tulasnellaceae with the rest of the Cantharellales. The inclusion of additional sequence

36 data did not clarify incongruences observed in previous studies of Rhizoctonia fungi in the

37 Cantharellales based on analyses of a single or multiple genes. The diversity of ecological and

38 morphological characters associated with these fungi requires further investigation on character

39 evolution for re-evaluating homologous and homoplasious characters.

42 Keywords: Rhizoctonia solani; multi-locus phylogeny; Rhizoctonia anamorphs; fungal plant 43 pathogens 


\section{Introduction}

The systematics and taxonomy of anamorphic fungi classified as Rhizoctonia have been in a constant state of flux since the original description of the genus by DeCandolle in 1815, which was based primarily on the ability of the fungi to infect plants and form sclerotia (Stalpers and Andersen 1996). However, these fungi can also grow as saprobes or as beneficial endomycorrhizal symbionts of orchids (Masuhara et al. 1993; Cubeta and Vilgalys 2000; Jiang et al. 2015). The study of Rhizoctonia fungi is largely associated with their economic importance as pathogens on more than 500 species of plants (Farr et al. 2005). Since $R$. solani and other described species of Rhizoctonia do not produce asexual spores, morphological characteristics of vegetative cells (hyphae and sclerotia), such as the absence of clamp connections, patterns of branching and constriction, number of nuclei per cell, pigmentation, and hyphal width, were initially used to classify and identify them. With the discovery that the fungus could undergo sexual reproduction (Prillieux and Delacroix 1891; Rolfs 1903), color, shape, and size of the sexual fruiting structures have also been used as taxonomic characters. This discovery also established the connection of the anamorph (asexual) and teleomorph (sexual) stages of the fungi. Subsequently, several different genera of resupinate fungi that include Botryobasidium Donk, Ceratobasidium D.P. Rogers, Thanatephorus Donk, Tulasnella J. Schröter, and Uthatobasidium Donk were found to be associated with a Rhizoctonia anamorph (Talbot 1970; Stalpers and Andersen 1996). However, morphological characters of the anamorph and teleomorph are variable and of limited value in defining and delimiting species (Andersen and Stalpers 1994; Roberts 1999; Vilgalys and Cubeta 1994).

The single most important criterion for delineating species of Rhizoctonia is referred to as the "anastomosis group concept" (Matsumoto et al. 1932; Richter and Schneider 1953; Schultz 
67 1936). This concept is based on the premise that hyphae of related isolates of the same species

68 (independent of their capability to mate) have the ability to recognize and fuse (i.e.

69 "anastomose") with each other. The anastomosis group (AG) concept has been used extensively

$70 \quad$ to examine $R$. solani (associated with a Thanatephorus teleomorph) and other species of

71 Rhizoctonia (e.g. Ceratorhiza) associated with a Ceratobasidium teleomorph (Ogoshi et al. 1983;

72 Parmeter et al. 1967; Carling 1996). At least 13 groups in Thanatephorus (designated as AG

73 followed by a number, AG-1 to AG-13) and 21 groups in Ceratobasidium (designated as AG

74 followed by a letter, AG-A to AG-U) have been described, but only 16 are currently used

75 (Sharon et al. 2008). These AGs have been further divided into subgroups using additional

76 biochemical, host association, nuclear condition of hyphal cells (binucleate or multinucleate) and

77 molecular criteria or have been re-defined such as AG-bridging isolate (BI), now considered as a

78 subgroup of AG-2 (=AG-2 BI, Carling et al. 2002). Although the formal taxonomic status of AG

79 and subgroups has been the subject of considerable debate, recent sequence analyses of the

80 internal transcribe spacer (ITS) and the large subunit (LSU) regions of the ribosomal DNA and

$81 \beta$-tubulin genes have provided support for the monophyly of the majority of these groups

82 (Cubeta et al. 1996; Kuninaga et al. 1997; González et al. 2001, 2006; Sharon et al. 2006, 2008).

83 More recently, higher phylogenies of the Kingdom Fungi have shown that Tulasnella

84 (anamorph=Epulorhiza), Botryobasidium (anamorphs=Allescheriella, Alysidium and

85 Haplotrichum), Ceratobasidium, Thanatephorus, and Uthatobasidium associated with the

86 anamorph name Rhizoctonia cluster within the Cantharellales, a clade that includes a collection

87 of taxa with extensive variation in lifestyles and morphology (Moncalvo et al. 2006, Hibbett et al.

88 2007; 2014). High variation is also observed in ribosomal RNA genes within the order. The first

89 efforts to circumscribe the order and identify monophyletic groups were made using sequence 
90 data from nuclear and mitochondrial rDNA (e.g. Hibbett and Thorn 2001, Binder et al. 2005,

91 Moncalvo et al. 2006). These studies documented the accelerated evolutionary rate heterogeneity

92 in these genes affecting phylogenetic reconstruction due to long-branch attraction. Other loci

93 with less unequal evolutionary rates, particularly protein coding genes and alternative

94 reconstruction methods were proposed for phylogenetic inferences within the Cantharellales (e.g.

95 Moncalvo et al. 2006, Matheny et al. 2007, Buyck and Hofstetter 2011).

96 In the past two decades there has been an ample discussion on the circumscription and

97 phylogenetic relationships within the Cantharellales, but problems still persist in the placement

98 of some members of the clade (readers interested in this subject should refer to Hibbett and

99 Thorn 2001, Larsson et al. 2004, Binder et al. 2005, Moncalvo et al. 2006, Hibbett et al. 2007,

100 Matheny et al. 2007; Hibbett et al. 2014). For example, the Ceratobasidiaceae is currently

101 considered a member of the order although its phylogenetic relationships are not well resolved

102 (Moncalvo et al. 2006, Hibbett et al. 2007; 2014). This family was restricted to the core taxa

103 Ceratobasidium, Thanatephorus and Uthatobasidium, but relationships among genera remain

104 unresolved. All previous research within the Ceratobasidiaceae have displayed only a limited

105 resolution not only for the scarce value of their morphological characters but because recognition

106 of Uthatobasidium as a valid genus remains controversial.

107 In a re-examination of the number of species belonging to the Ceratobasidiales sensu lato,

108 Roberts (1999) stated that species of Thanatephorus and Uthatobasidium are morphologically

109 similar and congeneric and should be synonymized, a taxonomic rearrangement that was

110 accepted by later researchers (Oberwinkler et al. 2013, Veldre et al. 2013). Molecular studies

111 have also shown that Uthatobasidium is not monophyletic and the distinction between

112 Uthatobasidium and Ceratobasidium requires further investigation (Binder et al. 2005; 
113 Moncalvo et al. 2006), as it is unclear whether the family contains two or three genera (Hibbett

114 et al. 2014). Therefore, Uthatobasidium fusisporum here is considered to be Thanatephorus

115 fusisporum. Phylogenies have also shown that the Ceratobasidiaceae represents a monophyletic

116 group sister to both Botryobasidium and other members of this clade (Binder et al. 2005; Hibbett

117 et al. 2007; Matheny et al. 2007; Moncalvo et al. 2006; Taylor and McCormick 2008). The

118 primary objective of this research was to develop a comprehensive multi-locus gene phylogeny

119 to understand the evolution and systematics of Rhizoctonia fungi and related resupinate taxa in

120 the Cantharellales. The following hypotheses were developed and tested: 1) the family

121 Ceratobasidiaceae is monophyletic; 2) Ceratobasidium and Thanatephorus represent well-

122 supported monophyletic groups in the Ceratobasidiaceae; and 3) Botryobasidium is the sister

123 group to the Ceratobasidiaceae.

125 2. Materials and Methods

126 2.1. Source of isolates

127 Fifty isolates were used in this study (Table 1). Isolates were obtained from

128 Departamento de Produção Vegetal - Setor de Defesa Fitossanitária da Faculdade de Ciências

129 Agronômicas -UNESP (SP, Brazil), the Centraalbureau voor Schimmelcultures - CBS- KNAW

130 (Utrecht, The Netherlands) and the culture collections from the Cubeta and Vilgalys laboratories.

131 All isolates were grown on potato dextrose agar (PDA) or malt extract agar (MEA) at $24{ }^{\circ} \mathrm{C}$ and

132 stored at $-80{ }^{\circ} \mathrm{C}$ in potato dextrose broth (PDB) with $50 \%$ glycerol.

133

134 2.2. DNA extraction and amplification 
To extract fungal DNA, isolates were grown on PDB, followed by lyophilization at room

136 temperature for 24-48 h. Lyophilized mycelium was ground in liquid nitrogen and nucleic acids

137 were extracted using either the DNeasy Plant Mini Kit column (Qiagen, Valencia, CA, USA) or

138 the extraction protocol published by Kuramae-Izioka (1997). PCR was used to amplify two

139 nuclear encoded genes (the second largest subunit of RNA polymerase II ( $r p b 2)$ and translation

140 elongation factor 1 alpha (tef1); one mitochondrial encoded gene, ATP synthase subunit 6 (atp6);

141 and two from the ribosomal DNA operon, the large subunit ribosomal DNA (LSU) and internal

142 transcribed spacer region (ITS). The general PCR protocols applied to all markers are described

143 in Table 2.

145 2.3. Amplicons sequencing

146 All PCR products were separated on agarose gel and purified prior to sequencing using

147 either the QIAquick PCR purification Kit (Qiagen, Valencia, CA, USA) or the GFX ${ }^{\mathrm{TM}}$ PCR

148 DNA gel band purification kit (Amersham Biosciences, Roosendaal, The Netherlands). When

149 possible sequencing reactions were performed directly on purified PCR products by using one of

150 the PCR primers used for amplification of a specific locus, but when necessary (due to the

151 presence of polymorphism and introns) PCR products were cloned using the TOPO.TA Cloning

152 Kit (Invitrogen, Grand Island, NY, USA) according to the manufacturer's instructions. Clones

153 were sequenced using the M13F and M13R primers. Sequencing reactions were performed using

154 Big Dye chemistry v3.1 (Applied Biosystems, Foster City, CA USA) and analyzed on an

155 Applied Biosystems 3730xl capillary sequencer. Sequence reads were trimmed and assembled

156 using Sequencher (Version 4.6, Gene Codes Corporation, Ann Arbor, MI, USA). Individual 
157 contigs were generated in Sequencher and BLAST (Altschul et al. 1990) was performed to

158 confirm the identity of sequenced products.

160 2.4. Phylogenetic analysis of DNA sequence data

Phylogenetic analyses of all loci were performed independently and in combination with

162 Maximum Parsimony (MP), Maximum Likelihood (ML) and Bayesian Phylogenetic Inference

163 (BPI). Independent matrices consisted of loci ITS and LSU from the ribosomal DNA operon (50

164 and 22 taxa respectively), the nuclear encoded genes $r p b 2$ and tefl (49 and 45 taxa respectively),

165 and the mitochondrial gene atp6 (40 taxa). The combined matrix included some taxa for which a

166 gene region is missing, however, for large alignments modest amounts of missing data generally

167 did not have a negative affect on the results of phylogenetic analyses (Wiens 2006). The multi-

168 locus data set emphasizes taxa within the Ceratobasidiaceae, whereas other members of the

169 Cantharellales were under-represented for these loci. A separate analysis for testing the

170 monophyly of the family was performed with only sequences of the $r p b 2$ locus available at

171 GenBank. This gene has been useful at higher taxonomic levels because it has a higher

172 phylogenetic informativeness compared with ribosomal genes and its conservation of amino acid

173 sequence facilitates alignment (e.g. Matheny et al. 2005, 2007; Schoch et al. 2009). Nucleotide

174 sequences were aligned using the MAFFT program (http://www.ebi.ac.uk/Tools/msa/mafft/),

175 which allows rapid detection of homologous segments using fast Fourier transform (FFT)

176 through an iterative refinement of an initial alignment. FASTA files were imported into Mesquite

177 version 3.0 (Maddison and Maddison 2014) for concatenation and trimming of sequence data.

178 Heuristic searches for MP were conducted in PAUP* 4.0b10 (Swofford 2002). Analyses

179 were executed with 1,000 random addition replicates and Tree-Bisection-Reconnection (TBR) 
180 branch swapping after exclusion of uninformative characters. Statistical support for branches was

181 calculated from 1,000 bootstrap replicates with TBR branch swapping and 10 heuristic searches

182 per replica. Model parameters for ML were determined using jModelTest 2.1.4 (Darriba et al.

183 2012). Analyses were accomplished with GARLI v. 1.0 (Zwickl 2006) with model parameters

184 fixed according values obtained with jModelTest (Supplementary Table S1). Searches consisted

185 of 10 replicates to ensure that results were consistent and reproducible. Branch support for ML

186 was determined simultaneously by doing 100 non-parametric bootstrap iterations in each of the

18710 replicates. BPI analyses were conducted using MrBayes 3.1.2 (Altekar et al. 2004;

188 Huelsenbeck and Ronquist 2001; Ronquist and Huelsenbeck 2003). Individual matrices were 189 analyzed with model GTR $+\Gamma(\mathrm{nst}=6$; rates $=$ gamma $)$, because the specific models generated

190 by jModelTest are not implemented in MrBayes. All trees were given equal weight $a$ priori. For 191 the concatenated matrix, sequences were partitioned by gene with a unique GTR $+\Gamma$ model for 192 each partition with unlinked parameters and allowing rates to vary across partitions. Each 193 analysis comprised two independent 1 to 10-million generation runs, with four chains (one cold 194 and three hot) each, until an average standard deviation of split frequencies of 0.01 or less was 195 reached (combined matrix only reached 0.07 after 10-million generation run). We sampled trees 196 every $100^{\text {th }}$ generation and discarded initial samples applying a "burn-in" value of $25 \%$ before 197 calculating the majority consensus tree and posterior probabilities (PP) for clades. Burn-in was 198 assessed using the stability of likelihood values within and between the duplicate runs. The 199 potential scale reduction factor (PSRF) was close to 1.000. For the concatenated and three 200 individual matrices (ITS-LSU, rpb2 and tef1) the taxon Tulasnella pruinosa (AFTOL ID 610) 201 was used as the outgroup. Because of our inability to sequence locus atp6 for T. pruinosa, 202 Clavulina sp., was used as the outgroup in the analysis for this locus. 
To examine the extent of genomic support and source of phylogenetic signal in the

204 concatenated matrix four approaches were used. First, we conducted a Bayesian Concordance

205 Analysis (BCA) using BUCKy 1.4.3 (Larget et al. 2010). In this analysis, individual gene trees

206 are summarized with mbsum (distributed within the BUCKy package) to provide a concordance

207 factor (CF) per clade that represents the proportion of gene trees that are in agreement (Wielstra

208 et al. 2014). Individual gene trees with all taxa (including with missing sequences) were

209 generated with MrBayes using a single eight-chain 50,000 generations run, sampled every 100

210 generations and applying a burn-in value of $25 \%$. The output of mbsum was further processed in

211 BUCKy to create a primary concordance tree with CFs for clades. Concordance factors are

212 reported for the default prior number $(\alpha)$ of 1 since we did not have any evidence for a priori

213 level of discordance among loci. Second, sensitivity analyses involving the inclusion or

214 exclusion of different locus were performed to determine the relative contribution of each gene

215 on the CF. Third, for determining conflict and congruence of each gene tree in the ML

216 concatenated tree topology, we compared manually each bipartition and recorded whether the

217 bipartition was concordant with or conflicted with each clade in the combined tree (Smith et al.

218 2015). Lastly, we calculate the Internode Certainty (IC), Internode Certainty All (ICA), Tree

219 Certainty (TC), and Tree Certainty All (TCA) adjusted for partial gene trees (Kobert et al. 2015),

220 by considering the frequency of all conflicting bipartitions $(0=$ maximum conflict; $1=$ strong

221 certainty) in the RAxMLHPC-AVX version. These measures have been proposed for quantifying

222 the degree of incongruence for a given internode, or for an entire tree in phylogenies inferred

223 from different data matrices (Kobert et al. 2015; Salichos and Rokas 2013; Salichos et al. 2014;

224 Stamatakis 2006). For performing this analysis, the unresolved branch (AG-10, AG-8,(AG-F,

225 AG-4 HGIII) in the ML concatenated tree had to be rearranged to the branch (AG-10, AG- 
8),( AG-F, AG-4 HGIII) for having a fully resolved bifurcated tree.

For testing the monophyly of the Ceratobasidiaceae, we conducted additional analyses with 165 sequences of rpb2 from representative taxa in the Cantharellales (Clavulina, Cantharellus, Craterellus, Hydnum, Botryobasidium, and Tulasnella) including representatives from Sebacinales and Auriculariales. Sequences selected were only those that were complete for the segment sequenced for the multi-locus analyses. Analyses were as follow: a) Parsimony Ratchet in NONA (PR; Goloboff, 1998) with 1000 iterations, holding 100 trees per iteration and with $10 \%$ of the characters perturbed; b) Maximum Likelihood with RAxML with default parameters and the GTRGAMMA substitution model; and c) BPI with two independent 4million generation runs, with four chains (one cold and three hot) each, sampling trees every $100^{\text {th }}$ generation and discarding a burn-in value of $25 \%$. Statistical support for the ML analysis was calculated from 1,000 bootstrap replicates. To explore the history of trophic behavior and nuclear division, maximum parsimony reconstruction of ancestral states were performed using Mesquite v. 3.0 (Maddison and Maddison 2014). Characters were coded with all transformations unordered and equally weighted from descriptions from the literature and personal communication from the authors. Trees were subsequently edited using Adobe illustrator $\mathrm{V}$ 16.0.0. The alignment and resulting trees from multi-locus gene analyses are deposited in TreeBASE (http://purl.org/phylo/treebase/phylows/study/TB2:S15006)

\section{Results}

\subsection{Single locus analyses}

A comparison of general features for phylogenetic analyses on nucleotide sequences from single and combined regions is summarized in Table 3. Individual gene topologies showed that 
groups associated with the genera Ceratobasidium and Thanatephorus were consistently

250 included in one large well-supported monophyletic group regardless of the method employed for

251 phylogenetic reconstruction. However, Ceratobasidium and Thanatephorus were not

252 monophyletic. Several small clades were consistent with previous anastomosis grouping based

253 on hyphal fusion (anastomosis) criteria. In most analyses, AG-1-IC, AG-2-2, AG-3, AG-9, AG-

254 A, AG-E, and AG-D were monophyletic. Topologies differed among individual gene

255 phylogenies. For example, Thanatephorus sp. CBS 293.31 was placed related to AG-4, AG-2-2

256 or AG-5 depending the locus analyzed; or Ceratobasidium sp. CBS 476.82 in some analyses was

257 related to Thanatephorus, while in others to isolates of Ceratobasidium (Supplementary Fig S1

258 A-D). The phylogenetic position of other representative members of the Cantharellales was also

259 uncertain in single locus analyses. For example, data from the ITS-LSU region clustered

260 Clavulina sp., Hydnum albomagnum and Botryobasidium simile in a small clade sister to the

261 Ceratobasidiaceae, while data from the rpb2 gene grouped Cantharellus cibarius, Clavulina sp.

262 and Hydnum albomagnum.

263 Analyses for testing the monophyly of the family was performed with 165 sequences and

264487 characters from which 318 were informative for parsimony ratchet. This analysis generated

26533627 trees of 3727 steps. Maximum Likelihood analysis with RAxML and the GTRGAMMA

266 substitution model resulted in a loglikelihood $(-\ln )$ score of -15822.8677 . The consensus tree

267 from the Parsimony Ratchet (PR) analysis was unresolved on early-diverging lineages within the

268 Cantharellales (topology not shown). However, Maximum Likelihood and Bayesian

269 Phylogenetic Inference recovered all families within the Cantharellales as monophyletic with

270 significant posterior probabilities, but lower bootstrap support. These analyses, with a more

271 extensive sampling of taxa also placed Botryobasidium (Botryobasidiaceae) as a sister group of 
272 the Ceratobasidiaceae as did single and multi-locus analyses, and moderately supported the sister

273 relationship of Tulasnellaceae with the rest of the Cantharellales (Fig 1).

274

275 3.2. Multi-locus gene phylogeny

Phylogenetic analyses of the concatenated data set employing three different methods for

277 phylogenetic reconstruction supported the hypothesis that the family Ceratobasidiaceae is

278 monophyletic and includes the genera Ceratobasidium and Thanatephorus. But as with

279 individual analyses, Ceratobasidium and Thanatephorus were not recovered as monophyletic.

280 Thanatephorus (syn. Uthatobasidium) fusisporum was closely related to species of

281 Ceratobasidium, contrasting with the proposition of the taxonomic rearrangement for

282 transferring it into Thanatephorus (Hauerslev and Roberts in Oberwinkler et al. 2013). Although

283 very similar, the clades recovered within the Ceratobasidiaceae have discrepancies depending on

284 the reconstruction method used (Fig 2). For example, all three phylogenetic reconstruction

285 methods placed T. fusisporum in distinct locations within the tree, and only MP analysis

286 recovered Thanatephorus praticola Kotila (=Rhizoctonia solani AG-4) as monophyletic with

287 low support (Fig 2). Only isolates from AG-4 HGI were recovered as monophyletic in most

288 analyses (Supplementary Table S2).

289 The concatenated matrix (ITS-LSU, rpb2, tef1 and atp6) included 50 taxa and 3318

290 characters from which 1339 were informative for MP analysis. This analysis generated two trees

291 of 6079 steps $(\mathrm{CI}=0.380 ; \mathrm{RI}=0.575$, Fig 3$)$. The best-fit substitution model for ML analysis

292 under the Akaike information criterion (AIC) was TIM3+I+G. Nucleotide frequencies and

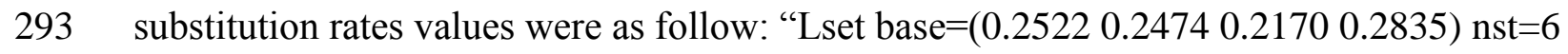

$294 \mathrm{rmat}=(0.75423 .16161 .00000 .75424 .2313)$ rates $=$ gamma shape $=0.3300 \mathrm{ncat}=4$ 
295 pinvar=0.0000". Analyses with these model parameters fixed resulted in a loglikelihood $(-\ln )$

296 score of -33315.3131 . The primary concordance tree generated with BCA using the independent

297 posterior probabilities of the individual gene trees is similar to the Bayesian tree generated with

298 the concatenated data set (Supplementary Fig S2). However, CF values were highly variable.

299 Values obtained go from as low as 0.001 up to 0.936 . Only 10 out 46 clades had CF values above

$300 \quad 0.5$ (Fig 3), reflecting discordance among individual gene trees. The CF values were in general,

301 lower on the branches representing earlier divergences.

302 In the sensitivity analyses, most clades were recovered in separate analyses with

303 mitochondrial (atp6) and nuclear markers (ITS-LSU, rpb2 and tef1) irrespective of the

304 reconstruction method used (Supplementary Table S2). However, the combination of $r p b 2$ and

305 tefl provided the highest concordance values (Supplementary Table S3). Analysis of concordant

306 bipartitions in the combined ML topology for Rhizoctonia fungi is presented in Fig 4. The

307 numbers of clades concordant with the concatenated tree at that node are mapped on branches.

308 Only eight small terminal clades were supported with more than two genes; the IC and ICA

309 measurements also showed that the highest values correspond to those clades. Several nodes had

310 values less than 1.0 in the concatenated phylogeny reflecting conflicts. Most had negative values

311 showing that the internode conflicted with one or more bipartitions having a higher frequency.

312 Values at or near -1 indicated absence of support for the bipartition defined by a given internode.

313 The TC and TCA values for the concatenated ML tree under uniform bipartition adjustment were

$314-11.352130$ and 1.984236 , respectively.

315 Tree topologies from all analyses showed shorter branch lengths of taxa within the family

316 when compared to those produced by other taxa of the Cantharellales included in the analyses.

317 Bootstrap and PP values provided consistent topology and statistical support for several higher 
318 relationships within the Ceratobasidiaceae. Ten strongly supported clades with the three metrics

319 of support above $80 \%$ were recovered (Fig 3, Clades I to X). These clades were recovered in

320 most analyses irrespective of the gene or combination of genes or the reconstruction method used

321 (Supplementary Table S2), but its position differed in all individual analyses (Supplementary Fig

322 S1 A-D). Clade I included all isolates of Thanatephorus sasakii AG-1-IC. This group was

323 accommodated in a larger clade supported by two of three measures containing T. sasakii (AG-1-

324 IB), T. pendulus (AG-1-IA) and Ceratobasidium sp. (CBS 476.82). Clades II and III consisted of

325 two isolates of Ceratobasidium AG-E and AG-P with AG-U, respectively. These three clades

326 were included in a larger clade with less support as clades II and III. Clade IV grouped two

327 isolates of Ceratobasidium (AG-R and AG-S). Clades V to VIII contained only species of

328 Thanatephorus, while clades IX and X clustered only species of Ceratobasidium. Eight isolates

329 of Ceratobasidium assembled with all but one isolate of Thanatephorus, within a strongly

330 supported clade that we designate as the thanatephoroid clade (Fig 3). Thanatephorus (syn.

331 Uthatobasidium) fusisporum was grouped with low support with species of Ceratobasidium

332 globisporum and C. sphaerosporum.

\section{4. Discussion}

The main objective of this study was to develop a comprehensive multi-locus gene phylogeny to better understand the evolution and systematics of Rhizoctonia fungi and related

337 resupinate taxa in the Cantharellales. Although, several molecular studies have delimited this

338 clade (e.g., Binder et al. 2005; Moncalvo et al. 2006) none of these previous studies have

339 provided an inclusive systematic treatment of Rhizoctonia fungi with other resupinate taxa.

340 Several new sequences were produced and combined with those available in public databases to 
341 perform multiple phylogenetic analyses from both separate and concatenated data sets. All of our

342 analyses indicated that the family Ceratobasidiaceae is monophyletic and supports hypothesis 1.

343 The monophyly of this family was also resolved in a recent analysis using publicly available ITS

344 sequences (Veldre et al. 2013). Their study also revealed that Ceratobasidium was paraphyletic

345 with at least three groups (AG-E, AG-P with AG-U and AG-R with AG-S) clustering together

346 with isolates of Thanatephorus. These results are consistent with our findings. Therefore,

347 hypothesis 2 that Ceratobasidium and Thanatephorus each represent a well-supported

348 monophyletic group was rejected. Our multi-locus analyses also indicate that Botryobasidium

349 (Botryobasidiaceae) is a sister group to the Ceratobasidiaceae and these findings provide support

350 for hypothesis 3. The position of Botryobasidiaceae as a sister group to the Ceratobasidiaceae is

351 also supported in our ML and BPI analyses with 165 sequences of the rpb2 locus (Fig 1).

352 However, PR analysis did not resolve relationships among the families within the Cantharellales.

353 A multilocus phylogeny with protein coding genes and multiple representatives of each family

354 would be necessary to confirm these relationships.

356 4.1. Phylogenetic relationships within Ceratobasidiaceae

357 Within the Ceratobasidiaceae, 10 inclusive well-supported monophyletic groups were

358 revealed (Fig 3 and Supplementary Table S2). In general, the groups were consistent with

359 previous separation based on hyphal fusion criteria and placement of isolates into anastomosis

360 groups (i.e., the AG concept). Clade I included only isolates of Thanatephorus belonging to AG-

361 1-IC. They were related to isolates from AG-1-IA, AG-1-IB and one isolate of Ceratobasidium

362 sp. CBS 476.82. All are plant pathogens associated with monocots that include rice, corn,

363 sorghum, turfgrass, and several dicots hosts such as peanut and soybean. This CBS number is 
364

365

366

367

368

369

370

371

372

373

374

375

376

377

378

379

380

381

382

383

384

385

386

associated to isolate BN 38 (CAG-4 anastomosis tester isolate, Burpee 1980) (CBS-KNAW

Fungal Biodiversity Centre, http://www.cbs.knaw.nl/) and is considered to belong to a subgroup of AG-F (Sharon et al. 2007).

Clades II to IV grouped two isolates of Ceratobasidium AG-E, AG-P with AG-U and AG-R and AG-S respectively (Fig 3). The close relationship existing within these isolates has been previously recognized (Hyakumachi et al. 2005; Rinehart et al. 2007; Sharon et al. 2008; Veldre et al. 2013). Isolates of AG-U have been found to recognize and undergo hyphal fusion (anastomose) with certain isolates of AG-P, and Sharon et al. (2008) have suggested that AG-U is a subgroup of AG-P. In their study, they recovered a cluster consisting of same AGs including AG-R and AG-S plus a subgroup of AG-F. Similar to our results, this group of Ceratobasidium spp., was located inside a major clade composed for only species of Thanatephorus (Sharon et al. 2008; Veldre et al. 2013). Related to clade IV but with no support was Thanatephorus sp. (AG-6 HGI). Although, Yokoyama and Ogoshi (1986) reported hyphal fusion among some isolates of Ceratobasidium AG-F and Thanatephorus AG-6 suggesting a possible genetic relationship based on somatic recognition, this connection of AG-6 HGI with AG-R and AG-S is ambiguous since the placement of AG-6 HGI changed in different analyses.

Clades V to VIII contained only species of Thanatephorus. Internal relationships within these clades are in general agreement with previous phylogenetic studies, but one novel supported relationship was revealed in Clade V between AG-5 and AG-7 (Fig 3). These relationships have not been previously observed or reported and AGs of additional isolates should be included to better justify their relationship.

Clade IX clustered only species of Ceratobasidium spp., two isolates of AG-A one binucleate species (DAOM 138188) that does not anastomose with others, and AG-G. Under the 
387 AG system developed in Japan, AG-A corresponds to CAG-2 (Ogoshi et al. 1983). Since the 388 teleomorph of CAG-2 was identified as Ceratobasidium cornigerum (Burpee et al. 1980), 389 isolates in this clade appear to belong to the same teleomorph species. The binucleate species 390 (DAOM 138188) has also been associated to AG-A (Ogoshi et al. 1983) and linked to $C$. 391 cornigerum, which is considered a genetically variable species (Burpee et al. 1980). It was 392 named Rhizoctonia endophytica (Saksena and Vaartaja 1960), but according to Andersen and 393 Stalpers (1994) is not a valid name. A relationship between Ceratobasidium AG-A and AG-G 394 has also been observed from pathogenic isolates from strawberry in Israel (Sharon et al. 2007), 395 and both AGs have been reported to cause similar symptoms on other plant species (e.g., 396 Mazzola 1997; Ogoshi et al. 1983).

398 CBS 223.51 from US and Japan, respectively, also formed a strongly supported smaller clade, 399 which may indicate a differentiation of AG-D into subgroups, as has been proposed (Priyatmojo 400 et al. 2001; Toda et al. 1999). Ceratobasidium sp. AG-Q was related to Clade X but with limited 401 support (Fig 3). The relationship of Ceratobasidium spp. AG-D and AG-Q agree with previous 402 molecular phylogenetic analyses that found strong support for a clade including both AGs 403 (González et al. 2001, 2006). This relationship has been also shown based on similarities in 404 RFLPs, RAPD and fatty acid analyses (Hyakumachi et al. 2005). A moderately supported small 405 clade grouped C. globisporum (AG-Bb, syn. Ceratobasidium oryzae-sativae) with $C$.

406 sphaerosporum. Warcup and Talbot $(1971,1980)$ described these taxa as the sexual stage for 407 isolates of Rhizoctonia sampled from orchids roots in Queensland. However, Roberts (1999) 408 suggested that several characters of these species overlap and may be morphological extremes of 409 a single taxon. $C$. oryzae-sativae is a less aggressive and damaging pathogen on rice than $R$. 
410 solani AG1-IA, but can produce similar lesions on the leaf sheath (Johanson et al. 1998).

411 Thanatephorus (syn. Uthatobasidium) fusisporum was also included in this clade but with no

412 support and the taxonomic position of this isolate within the family was ambiguous. There were

413 disagreements in its placement depending on the gene and reconstruction method used.

414 Therefore, the inclusion of additional isolates of this species is required to improve their

415 phylogenetic relationships and to clarify if the family contains two or three genera.

417 4.2. Gene discordance

418 The BCA analysis revealed concordance factors less than 1 for several clades. Thirty-six

419 of 46 clades had CF values below 0.5 reflecting discordance among individual gene trees.

420 Although, discordance has been observed in rapidly and recently derived taxa (Nosenko et al.

421 2013; Wielstra et al. 2014), in the Rhizoctonia species complex part of the discordance is likely

422 due to those taxa with missing data in individual gene matrices (Table 3). BCA analyses must be

423 performed with same number of taxa. Therefore, missing data were coded with interrogation

424 points (e.g., ?), which influenced the concordance value. Nevertheless, the resulting concordance

425 tree provides an estimate of the discordance and divergence at various points in the history of the

426 Cantharellales (Supplementary Fig S2). Although internal lineages in the Ceratobasidiaceae still

427 deserve careful scrutiny, there were several terminal clades with high concordance values,

428 regardless of the combination of genes analyzed (Supplementary Table S3). As in bootstrap or

429 BPI support values, low concordance was mainly on branches representing earlier divergences.

430 Therefore, processes including hybridization, introgression, recombination, horizontal/lateral

431 gene transfer, incomplete lineage sorting, etc., may be influencing the low gene concordance

432 values in the Rhizoctonia species complex. However, assemblage of sequence data from more 
433 loci with higher concordance, and inclusion of more taxa are needed to establish which

434 evolutionary processes have shaped the observed gene discordance. Not surprisingly, the number

435 of gene regions that support a specific clade is related to the concordance factor (Fig 4 and

436 Supplementary Fig S2). However, there were clades with low concordance factors that received

437 high support in the analysis of concatenated data (Fig 3), emphasizing the distinction between

438 concordance factors and support values such as bootstrap (Salichos and Rokas 2013).

$439 \quad$ Fontenot et al. (2011) has observed that species affected by natural hybridization often

440 demonstrate patterns of discordance between phylogenies generated using nuclear and

441 mitochondrial markers, but in our sensitivity analyses inclusion or exclusion of mitochondrial

442 data (atp6) had limited impact irrespective of the reconstruction method used (Supplementary

443 Table S2, columns E and G). However, many important deep relationships remained unresolved

444 despite our increased sampling of gene regions and inclusion of more sophisticated analyses

445 compared with previous studies (González et al. 2001).

446 The IC, ICA, TC and TCA values reflected that the genetic loci sampled had conflicted

447 histories. They were incongruent at internodes in the set of gene trees and between the individual

448 gene trees across the entire phylogeny. Overall, concatenated trees did not reflect the

449 evolutionary histories of these loci. There was only a small set of relationships within the

450 Rhizoctonia fungi that appeared to be robustly supported by this data.

451 In general, previous research with these taxa have displayed only a limited resolution or

452 unsupported branches; causing their phylogenetic relationships to remain unresolved. Therefore,

453 it is important for future studies to design strategies to distinguish the causes that may be

454 influencing the low concordance values of genes in this group. This experimental approach will

455 contribute to understanding the evolutionary relationships and evolutionary processes involved in 
456 the diversification of this complex group of fungi. represent the most studied genera because of their economic importance as plant pathogens.

462 functioning as beneficial endomycorrhizal symbionts of orchids. In this study, ancestral states of 463 trophic behavior could not be reconstructed with certainty within the Cantharellales. Early464 divergent lineages were unresolved or unsupported. However, most analyses placed Botryobasidium (Botryobasidiaceae) as a sister group of the Ceratobasidiaceae. In the context of 466 the concatenated phylogeny, trophic behavior represents a challenging homology problem since 467 many taxa can have multiple modes of nutrition (Supplementary Fig S3) and we were very 468 cautious in interpreting this data. Almost all isolates can exist as saprobes, even the species that 469 associate with orchids. However, some isolates in different AGs are better competitive saprobes 470 than others. There are also differences in aggressiveness (virulence) of isolates that belong to 471 different AG. On some plant hosts Ceratobasidium and Thanatephorus can cause severe disease 472 and on others they cause limited to no disease. Consequently, the ecological role and trophic

473 behavior of Rhizoctonia fungi are challenging to discern because of their overlapping niches and 474 ability to associate with many plant hosts. Nonetheless, an examination of the ecological habitat 475 and trophic behavior associated with isolates and AG groups comprising each of the lineages 476 identified in this study provided a glimpse into the lifestyles common to each of these clades. Isolates of Clade I represent the most important pathogens of major agricultural crops 478 worldwide, such as rice, sorghum, corn, peanut, cabbage, and soybean (Fig 3). In contrast, 
479 isolates grouped into Clades II to IV are most often associated with woody plant hosts and have 480 been previously shown to cause root and stem diseases of ornamental plant species (Hietala and 481 Sen 1996; Hyakumachi et al. 2005). Clade V is composed of isolates of Thanatephorus spp., 482 AG-5 and AG-7 that are predominantly described as non-aggressive pathogens of apple, legumes, 483 sugar beet, and potato (e.g., Lehtonen et al. 2008; Mazzola et al. 1996, 1997; Sneh et al. 1991;

484 Windels et al. 1997). However, isolates belonging to AG-5 have also been found to be beneficial 485 to orchids (Andersen and Rasmussen 1996; Carling et al. 1999). Clade VI grouped isolates belonging to Thanatephorus spp., AG-2-2 IIIB and AG-2-2 IV. 487 These fungi cannot be distinguished based on hyphal fusion criteria and mainly cause sheath 488 blight of grasses and root rot of sugar beet, respectively (Hyakumachi et al. 1998; Ogoshi 1987). 489 In a recent study with publicly available ITS sequences, Veldre et al. (2013) found that AG-2 490 was polyphyletic. This result was similar to what we observed in this study, since subgroup AG491 2-1 did not cluster with AG-2-2 (Fig 3). Clade VII is composed of isolates belonging to 492 Thanatephorus AG-9, AG-2-1 and AG-3 that have been predominantly reported as pathogens of 493 plants in the family Solanaceae (e.g., Bartz et al. 2010; Lehtonen et al. 2008; Woodhall et al. 494 2007; Yanar et al. 2005).

495 Isolates belonging to AG-4 (Clade VIII) are generalist pathogens of plants and cause seed 496 rot, and pre- and post emergence damping-off of seedlings (Kuramae et al. 2003; Liao et al. 497 2012; Polizzi et al. 2011). Isolates linked to C. cornigerum and Ceratobasidium sp., AG-G found 498 in Clade IX are also plant pathogens of a variety of host plants, but in contrast to isolates of AG4994 , they can grow endophytically in roots without causing disease symptoms. Isolates grouped 500 within Clade X (Ceratobasidium sp. AG-D) are pathogens of cereals and turfgrasses, and several 501 other species of plants outside of the order Poales, such as sugar beet, cotton, bean and mat rush. 
Inference of ancestral state suggests that plant pathogenic groups of Rhizoctonia may

503 possibly be derived from a mycorrhizal ancestor since the Ceratobasidiaceae represents the only

504 recognized lineage in the Cantharellales that contain plant pathogenic species. Recent studies

505 with public ITS sequences of Rhizoctonia fungi in the family Ceratobasidiaceae have also

506 suggested that pathogenic groups were derived from putative soil saprobes (Sharon et al. 2006,

507 Veldre et al. 2013). The discovery that the lichen associated fungus Burgoa clusters near

508 Ceratobasidium and Thanatephorus in the Cantharellales is intriguing (Lawrey et al. 2007), since

509 these species are parasites of the green algal component of lichens. Future analysis of the

510 position of this taxon within the Cantharellales could provide novel insight about the evolution of

511 parasitic lifestyles on plants. Taken collectively, these circumstantial pieces of evidence suggest

512 that pathogenicity might be rapidly and recently derived in Rhizoctonia fungi. Our current

513 phylogenies support this hypothesis, as they revealed the presence of many short branches in

514 nearly all of the isolates analyzed (Fig 2), and individual gene phylogenies have increased

515 support for terminal nodes. Therefore, the rapid divergence in the presence of agricultural

516 practices may have contributed to the expansion and diverse ecology of the pathogenic species in

517 the Rhizoctonia complex. However, some lineages within the Ceratobasidiaceae are also known

518 to establish beneficial endomycorrhizal associations with orchids (Jiang et al. 2015; Rasmussen

519 1995; Taylor and McCormick 2008; Warcup 1985, 1991). Endomycorrhizal associations of

520 orchids and liverworts are also commonly found in another member of the Cantharellales, the

521 resupinate genus Tulasnella (Andersen and Rasmussen 1996; Bidartondo et al. 2003; Kottke et al.

522 2003; Sikaroodi et al. 2001). Interestingly, Yagame and colleagues (2008, 2012) have reported

523 that isolates of Ceratobasidium sampled from rhizomes of achlorophyllous orchids can also form

524 ectomycorrhizae with pines suggesting that the orchid is able to access photosynthates from 
525 adjacent trees.

526 The diversity in ecology, life history and trophic behavior coupled with a worldwide

527 distribution suggests that Rhizoctonia fungi may represent an ancient lineage that has evolved

528 complex relationships with soil microorganisms and plants, ultimately contributing to its success

529 in both time and space (Baker 1970). The phylogenetic framework generated in this study shows

530 that for a better understanding of adaptation of these fungi, further work is needed on saprobic

531 and endomycorrhizal groups within each AG on distribution, population genetic diversity and

532 host plant interactions. Furthermore, as this study and others have revealed Rhizoctonia fungi

533 appear to contain a great diversity of cryptic species (Taylor and McCormick 2008; Veldre et al.

534 2013). Therefore, additional taxonomic and molecular systematics research that includes specific

535 isolates of Rhizoctonia fungi with previously well-documented trophic behavior coupled with

536 functional genes associated with this behavior are warranted.

537 As stated previously, ancestral states could not be reconstructed with certainty within the

538 Cantharellales in this study. All methods for inferring the states at the ancestral nodes assume a

539 specific tree and set of branch lengths when estimating the ancestral character state (Royer-

540 Carenzi et al. 2013). Therefore, inferences of ancestral states are conditioned on the tree and

541 branch lengths being true. Uncertainty in the phylogenies contributes to making ancestral state

542 reconstruction ambiguous. On the other hand, it has also been observed that even for cases where

543 the phylogeny is well supported, the uncertainty in parameters of the phylogenetic model, such

544 as the branch lengths on the tree and the substitution parameters, can be large, making ancestral

545 state reconstruction also unreliable (Huelsenbeck and Bollback 2001). Therefore, in the context

546 of our concatenated phylogeny the reconstruction of ancestral states for any character represents 
547 a homology problem (Supplementary Fig S3) since many taxa can have multiple lifestyles and

548 modes of nutrition.

550 4.4 Morphological complexity in the Cantharellales

551 The phylogenies presented in Figures 1 to 3, agree with previous conclusions of a

552 variable mixture of genetically divergent taxa within the Cantharellales (Binder et al. 2005;

553 Moncalvo et al. 2006). This diversity of taxa creates challenges for inferring the pattern of

554 morphological transformations. For example, the recent analyses of orchid endomycorrhizal

555 species with molecular data placed a species of the wood-associate fungus Sistotrema with clamp

556 connections within the Ceratobasidiaceae (Kristiansen et al. 2001; Taylor and McCormick 2008),

557 a group of fungi that do not usually produce these hyphal structures. However, this finding that a

558 species of Sistotrema, a highly polyphyletic genus, clusters near Ceratobasidium and

559 Thanatephorus is not well supported and needs further investigation.

560 The Cantharellales includes cantharelloid to agaricoid, hydnoid, coralloid, clavaroid, and

561 corticioid fungi (Hibbett and Thorn 2001). The basidium morphology and number of sterigmata

562 is also highly variable. Basidial forms range from short cylindrical or subcylindrical as in

563 Botryobasidium to elongate cylindrical as in Clavulina, and with sterigmata as variable as 2 to 8

564 (Binder et al. 2005), and basidia may be free or occur in clusters as in Botryobasidium (Langer et

565 al. 2000). The ample variation observed in this trait indicates that there have been numerous

566 morphological transformations within the Cantharellales, which creates challenges for using

567 these characters for delimiting genera in taxonomic analyses. However, within Ceratobasidiaceae

568 basidial morphology is more homogeneous as most species have short uniform basidia with 2-8

569 sterigmata. 
One character that appears to be a synapomorphy within the morphologically diverse

571 Cantharellales is stichic (rather than chiastic) nuclear division (Larsson et al. 2004; Pine et al.

572 1999). This character appears to generally support the derived status (Supplementary Fig S3).

573 However, information related to this nuclear division character within the Botryobasidiaceae and

574 Ceratobasidiaceae is still lacking (Moncalvo et al. 2006) and in need of revision since originally

575 the genus considered Uthatobasidium placed in synonymy to Thanatephorus by Roberts (1999),

576 was described as having non-stichic nuclear division (Tu et al. in Langer 2001). Tulasnella

577 occurring as a sister group to the rest of the Cantharellales has also been reported to display non-

578 stichic nuclear division (Penancier in Moncalvo et al. 2006). Consequently, these observations

579 suggest that the transformations between characters states of this cytological character have

580 occurred more than once. Therefore, further cytological studies are needed to investigate nuclear

581 division in members of the Botryobasidiaceae and Ceratobasidiaceae to gain more insight into

582 the evolution of this character.

583 Our study has contributed to a better and more comprehensive understanding of the

584 phylogenetic relatedness of fungi with Rhizoctonia anamorphs in the Cantharellales. The

585 analyses presented in this study provide a robust hypothesis for the monophyly of the

586 Ceratobasidiaceae. However, neither Ceratobasidium or Thanatephorus are monophyletic. Our

587 phylogenetic hypotheses also indicated that the Botryobasidiaceae is a sister group of

588 Ceratobasidiaceae, and that the Tulasnellaceae is sister to the rest of the Cantharellales. However,

589 these relationships need further investigation since some discrepancies were found depending on

590 the reconstruction method used. Our results also showed that the multi-locus gene phylogeny

591 was advantageous in resolving some relationships by combining the corresponding support for

592 different nodes from different gene partitions in terminal nodes. Unfortunately, additional data 
593 did not recover all incongruences observed in previous studies. The shorter branches found in

594 recently derived taxa within the Ceratobasidiaceae help in part to explain disagreements in the 595 taxonomy of Rhizoctonia fungi. Nonetheless, it is important for future studies to use more

596 concordant loci for avoiding gene conflict topologies in early-diverging lineages, and to

597 determine which evolutionary processes are causing discordance. A more robust phylogeny

598 would also be useful to test alternative analytic methods more recently developed for

599 reconstructing ancestral states of characters. The diversity of morphological and ecological

600 characters observed within these fungi requires further research on character evolution for re-

601 evaluating homologous and homoplasious characters within Rhizoctonia anamorphs in this clade.

602

603 Acknowledgments

604 The authors gratefully acknowledge Faith Bartz, Don Carling, Paulo Ceresini, Nikki

605 Charlton, Pedro Crous, Jesse Glaeser, and Suha Jabaji for providing cultures, and the technical

606 advice and assistance of Elizabeth Thomas and Suman Pakala. This project was supported by

607 grant no. 2010-34500-21676 from the United States Department of Agriculture (USDA) National

608 Institute of Food and Agriculture and USDA CRIS project 5368-21220-002-00D to MAC, the

609 National Institute of Health Molecular Mycology Pathogenesis Training Grant (\#T32 AI 52080)

610 to Thomas G. Mitchell (Duke University), and CONACyT 103158 to DG. Publication number

6115933 of the NIOO-KNAW, Netherlands Institute of Ecology.

612

613 References

614

615 Altekar G, Dwarkadas S, Huelsenbeck JP, Ronquist F, 2004. Parallel Metropolis-coupled 
616

617

618

619

620

621

622

623

624

625

626

627

628

629

630

631

632

633

634

635

636

637

638

Markov chain Monte Carlo for Bayesian phylogenetic inference. Bioinformatics 20: 407415.

Altschul SF, Gish W, Miller W, Myers EW, Lipman DJ, 1990. Basic local alignment search tool. Journal of Molecular Biology 215: 403-410.

Andersen TF, Stalpers JA, 1994. A checklist of Rhizoctonia epithets. Mycotaxon 51: 437-457.

Andersen TF, Rasmussen HN, 1996. A comparative taxonomic study of Rhizoctonia sensu lato employing morphological, ultrastructural and molecular methods. Mycological Research 100: $1117-1128$.

Baker KF, 1970. Types of Rhizoctonia diseases and their occurrence. In: Parmeter JR Jr. (ed) Rhizoctonia solani, biology and pathology. California University Press, Berkeley, CA, pp 125-148.

Bartz FE, Cubeta MA, Toda T, Naito S, Ivors KL, 2010. An in planta method for assessing the role of basidiospores in Rhizoctonia foliar disease of tomato. Plant Disease 94: 515-520.

Bidartondo MI, Bruns TD, Weiss M, 2003. Specialized cheating of the ectomycorrhizal symbiosis by an epiparasitic liverwort. Proceedings of the Royal Society B 270: 835-842.

Binder M, Hibbett DS, Larsson KH, Larsson E, Langer E, Langer G, 2005. The phylogenetic distribution of resupinate forms across the major clades of mushroom-forming fungi (Homobasidiomycetes). Systematics and Biodiversity 3: 1-45.

Burpee LL, Sanders PL, Cole H Jr, Sherwood RT, 1980. Anastomosis groups among isolates of Ceratobasidium cornigerum and related fungi. Mycologia 72: 689-701.

Buyck B, Hofstetter V, 2011. The contribution of tef-1 sequences to species delimitation in the Cantharellus cibarius complex in the southeastern USA. Fungal Diversity 49: 35-46.

Carling DE, 1996. Grouping in Rhizoctonia solani by hyphal anastomosis. In: Sneh B, Jabaji- 
Hare S, Neate S, Dijst G (eds) Rhizoctonia species taxonomy, molecular biology, ecology, pathology and disease control. Kluwer Academic Publishers, The Netherlands, pp 37-47.

Carling DE, Pope EJ, Brainard KA, Carter DA, 1999. Characterization of mycorrhizal isolates of Rhizoctonia solani from an orchid, including AG-12, a new anastomosis group. Phytopathology 89: 942-946.

Carling DE, Kuninaga S, Brainard KA, 2002. Hyphal anastomosis reactions, rDNA-internal transcribed spacer sequences, and virulence levels among subsets of Rhizoctonia solani anastomosis group-2 (AG-2) and AG-BI. Phytopathology 92: 43-50.

Cubeta MA, Vilgalys R, 2000. Rhizoctonia. In: Lederberg J (ed) Encyclopedia of Microbiology, vol 4. Academic Press, San Diego, pp 109-116.

Cubeta MA, Vilgalys R, González D, 1996. Molecular analysis of ribosomal RNA genes in Rhizoctonia fungi. In: Sneh B, Jabaji-Hare S, Neate S, Dijst G (eds), Rhizoctonia species: taxonomy, molecular biology, ecology, pathology and disease control. Kluwer Academic Publishers, The Netherlands, pp 81-86.

Cubeta MA, Thomas E, Dean RA, Jabaji S, Neate SM, Tavantzis S, Toda T, Vilgalys R, Bharathan N, Fedorova-Abrams N, Pakala SB, Pakala SM, Zafar N, Joardar V, Losada L, Nierman WC. 2014. Draft genome sequence of the plant-pathogenic soil fungus Rhizoctonia solani anastomosis group 3 strain Rhs1AP. Genome Announcements. 2(5):e1072-14. doi:10.1128/genomeA.01072-14.

Darriba D, Taboada GL, Doallo R, D. DP, 2012. jModelTest 2: more models, new heuristics and parallel computing. Nature Methods 9: 772.

Farr DF, Rossman AY, Palm ME, McCray EB, 2005. Fungal Database. Systematic Botany and Mycology Laboratory, ARS, USDA. http://nt.ars-grin.gov/fungaldatabases/ 
662 Fontenot BE, Makowsky R, Chippindale PT, 2011. Nuclear-mitochondrial discordance and gene flow in a recent radiation of toads. Molecular Phylogenetics and Evolution 59: 66-80.

664 González D, Carling DE, Kuninaga S, Vilgalys R, Cubeta MA, 2001. Ribosomal DNA systematics of Ceratobasidium and Thanatephorus with Rhizoctonia anamorphs. Mycologia 93: 1138-1150.

González D, Cubeta MA, Vilgalys R, 2006. Phylogenetic utility of indels within ribosomal DNA and beta-tubulin sequences from fungi in the Rhizoctonia solani species complex. Molecular Phylogenetics and Evolution 40: 459-470.

Goloboff PA, 1998. NONA. Computer program and software. Published by the author. INSUE Fundación e Instituto Miguel Lillo Miguel Lillo 205, 4000 S. M. de Tucumán, Argentina. http://www.cladistics.com/aboutNona.htm

Hibbett DS, Thorn RG, 2001. Basidiomycota: Homobasidiomycetes. In: McLaughlin DJ, McLaughlin EG, Lemke PA (eds), The Mycota. VIIB. Systematics and Evolution. Springer-Verlag, Berlin, pp 121-168.

Hibbett DS, Binder M, Bischoff JF, Blackwell M, Cannon PF, Eriksson OE, Huhndorf S, James T, Kirk PM, Lücking R, Lumbsch HT, Lutzoni F, Matheny PB, McLaughlin DJ, Powell MJ, Redhead S, Schoch CL, Spatafora JW, Stalpers JA, Vilgalys R, Aime MC, Aptroot A, Bauer R, Begerow D, Benny GL, Castlebury LA, Crous PW, Dai Y-C, Gams W, Geiser DM, Griffith GW, Gueidan C, Hawksworth DL, Hestmark G, Hosaka K, Humber RA, Hyde KD, Ironside JE, Kõljalg U, Kurtzman CP, Larsson K-H, Lichtwardt R, Longcore J, Miadlikowska J, Miller A, Moncalvo J-M, Mozley-Standridge S, Oberwinkler F, Parmasto E, Reeb V, Rogers JD, Roux C, Ryvarden L, Sampaio JP, Schüßler A, Sugiyama J, Thorn RG, Tibell L, Untereiner WA, Walker C, Wang Z, Weir A, Weiss M, 
White MM, Winka K, Yao Y-J, Zhang N, 2007. A higher-level phylogenetic classification of the fungi. Mycological Research 111: 509-547.

Hibbett DD, Bauer R, Binder M, Giachini AJ, Hosaka K, Justo A, Larsson E, Larsson KH, Lawrey JD, Miettinen O, Nagy L, Nilsson RH, Weiss M, Thorn RG, 2014. Agaricomycetes. In: McLaughlin JD, Spatafora JW (eds), The Mycota, vol. VII, Second Ed, Part A. Systematics and Evolution, Springer Verlag, pp. 373-429.

Hietala AM, Sen R, 1996. Rhizoctonia spp. associated with forest trees. In: Sneh B, Jabaji-Hare S, Neate S, Dijst G (eds), Rhizoctonia species: taxonomy, molecular biology, ecology, pathology and disease control. Kluwer Academic Publishers, The Netherlands, pp 351358.

Huelsenbeck JP, Ronquist F, 2001. MRBAYES: Bayesian inference of phylogenetic trees. Bioinformatics 17: 754-755.

Huelsenbeck JP, Bollback JP, 2001. Empirical and hierarchical Bayesian estimation of ancestral states. Systematic Biology 50: 351-366.

Hyakumachi M, Mushika T, Ogiso Y, Toda T, Kageyama K, Tsuge T, 1998. Characterization of a new cultural type (LP) of Rhizoctonia solani AG2-2 isolated from warm-season turfgrasses, and its genetic differentiation from other cultural types. Plant Pathology 47: $1-9$.

Hyakumachi M, Priyatmojo A, Kubota M, Fukui H, 2005. New anastomosis groups, AG-T and AG-U, of binucleate Rhizoctonia spp. causing root and stem rot of cut-flower and miniature roses. Phytopathology 95: 784-792.

Jiang JH, Lee YI, Cubeta MA, Chen LC, 2015. Characterization and colonization of endomycorrhizal Rhizoctonia fungi in the medicinal herb Anoectochilus formosanus 
(Orchidaceae). Mycorrhiza DOI 10.1007/s00572-014-0616-1

709

710

711

712

713

714

715

716

717

718

719

720

721

722

723

724

725

726

727

728

729

730

Johanson A, Turner HC, McKay GJ, Brown AE, 1998. A PCR-based method to distinguish fungi of the rice sheath-blight complex, Rhizoctonia solani, $R$. oryzae and $R$. oryzae-sativae. FEMS Microbiology Letters 162: 289-294.

Kobert K, Salichos L, Rokas A, Stamatakis A, 2015. Computing the internode certainty and related measures from partial gene trees. doi.org/10.1101/022053.

Kottke I, Beiter A, Weiß M, Haug I, Oberwinkler F, Nebel M, 2003. Heterobasidiomycetes form symbiotic associations with hepatics: Jungermanniales have sebacinoid mycobionts while Aneura pinguis (Metzgeriales) is associated with a Tulasnella species. Mycological Research 107: 957-968.

Kretzer A, Bruns TD, 1999. Use of atp6 in fungal phylogenetics: an example from the Boletales. Molecular Phylogenetics and Evolution 13: 483-492.

Kristiansen KA, D DLT, KjØller R, Rasmussen HN, Rosendahl S, 2001. Identification of mycorrhizal fungi from single pelotons of Dactylorhiza majalis (Orchidaceae) using single-strand conformation polymorphism and mitochondrial ribosomal large subunit DNAsequences. Molecular Ecology 10: 2089-2093.

Kuninaga S, Natsuaki T, Takeuchi T, Yokosawa. R, 1997. Sequence variation of the rDNA ITS regions within and between anastomosis groups in Rhizoctonia solani. Current Genetics 32: $237-243$.

Kuramae EE, Buzeto AL, Ciampi MB, Souza NL, 2003. Identification of Rhizoctonia solani AG 1-IB in lettuce, AG 4 HG-I in tomato and melon, and AG 4 HG-III in broccoli and spinach, in Brazil. European Journal of Plant Pathology 109: 391-395.

Kuramae-Izioka EE, 1997. A rapid, easy and high yield protocol for total genomic DNA 

isolation of Colletotrichum gloeosporioides and Fusarium oxysporum. Revista UNIMAR 19: 683-689.

733 Langer E, 2001. Phylogeny of non-gilled and gilled basidiomycetes DNA sequence inferrence, 734 ultrastructure and comparative morphology [Habilitation], Tuebingen University, 735 Tuebingen, Germany

Langer G, Langer E, Chen C-J, 2000. Botryobasidium musaisporum sp. nov. collected in Taiwan. Mycological Research 104: 510-512.

Larget BR, Kotha SK, Dewey CN, Ané C, 2010. BUCKy: Gene tree/species tree reconciliation with Bayesian concordance analysis. Bioinformatics 26, 2910-2911.

Larsson K-H, Larsson E, Kõljalg U, 2004. High phylogenetic diversity among corticioid homobasidiomycetes. Mycological Ressearch 108: 983-1002.

Lawrey JD, Binder M, Diederich P, Molina MC, Sikaroodi M, Ertz D, 2007. Phylogenetic diversity of lichen-associated homobasidiomycetes. Molecular Phylogenetics and Evolution 44: 778-789.

Lehtonen M, Ahvenniemi P, Wilson PS, German-Kinnari M, Valkonen JPT, 2008. Biological diversity of Rhizoctonia solani (AG-3) in a northen potato-cultivation environment in Finland. Plant Pathology 57: 141-151.

Liao X, Fu Y, Zhang S, Duan YP, 2012. First report of damping-off on Basella rubra caused by Rhizoctonia solani anastomosis group 4 in Florida. Plant Disease 96: 288.

Litvintseva AP, Thakur R, Vilgalys R, Mitchell TG, 2006. Multilocus sequence typing reveals three genetic subpopulations of Cryptococcus neoformans var. grubii (Serotype A), including a unique population in Botswana. Genetics 172: 2223-2238.

Liu Y, Whelen S, Hall B, 1999. Phylogenetic relationships among ascomycetes: evidence from 
an RNA polymerase II subunit. Molecular Biology and Evolution 16: 1799-1808.

755 Maddison DR, Maddison WP, 2014. Mesquite: a modular system for evolutionary analysis, 3.0.

756 http://mesquiteproject.org.

757 Masuhara G, Katsuya K, Yamaguchi K, 1993. Potential for symbiosis of Rhizoctonia solani and binucleate Rhizoctonia with seeds of Spiranthes sinensis var. amoena. Mycological Ressearch 97: 746-752.

Matheny PB, 2005. Improving phylogenetic inference of mushrooms with RPB1 and RPB2 nucleotide sequences (Inocybe; Agaricales). Molecular Phylogenetics and Evolution 35:

Matheny PB, Wang Z, Binder M, Curtis JM, Lim YW, Nilsson RH, Hughes KW, Hofstetter V, Ammirati JF, Schoch CL, Langer E, Langer G, McLaughlin DJ, Wilson AW, Frøslev T, Ge ZW, Kerrigan RW, Slot JC, Yang ZL, Baroni TJ, Fischer M, Hosaka K, Matsuura K, Seidl MT, Vauras J, Hibbett DS, 2007. Contributions of rpb2 and tef1 to the phylogeny of mushrooms and allies (Basidiomycota, Fungi). Molecular Phylogenetics and Evolution

Mazzola M, Smiley RW, Rovira AD, Cook RJ, 1996. Characterization of Rhizoctonia isolates, disease occurrence and management in cereals. In: Sneh B, Jabaji-Hare S, Neate S, Dijst G (eds) Rhizoctonia species: taxonomy, molecular biology, ecology, pathology and disease control. Kluwer Academic Publishers, The Netherlands, pp 259-267. 
777 Mazzola M, 1997. Identification and pathogenicity of Rhizoctonia spp. isolated from apple roots $778 \quad$ and orchard soils. Phytopathology 87: 582-587.

779 Moncalvo J-M, Nilsson RH, Koster B, Dunham SM, Bernauer T, Matheny PB, Porter TM,

780 Margaritescu S, Weiß M, Garnica S, Danell E, Lamger G, Langer E, Larsson E, Larsson

$781 \quad \mathrm{~K}-\mathrm{H}, 2006$. The cantharelloid clade: dealing with incongruent gene trees and

782 phylogenetic reconstruction methods. Mycologia 98: 937-948.

783 Nosenko, T., Schreiber, F., Adamska, M., Adamski, M., Eitel, M., Hammel, J., Maldonado, M.,

784 Müller, W.E.G., Nickel, M., Schierwater, B., Vacelet, J., Wiens, M., Wörheide, G., 2013.

785 Deep metazoan phylogeny: when different genes tell different stories. Molecular

$786 \quad$ Phylogenetics and Evolution 67, 223-233.

787 Oberwinkler F, Riess K, Bauer R, Kirschner R, Garnica S, 2013. Taxonomic re-evaluation of the

$788 \quad$ Ceratobasidium-Rhizoctonia complex and Rhizoctonia butinii, a new species attacking

$789 \quad$ spruce. Mycological Progress 12: 763-776.

790 Ogoshi A, Oniki M, Araki T, Ui T, 1983. Studies on the anastomosis groups of binucleate Rhizoctonia and their perfect states. Journal of the Faculty of Agriculture Hokkaido University 61: 244-260.

793 Ogoshi A, 1987. Ecology and pathogenicity of anastomosis and intraspecific groups of

Parmeter JR Jr., Whitney HS, Platt WD, 1967. Affinities of some Rhizoctonia species that resemble mycelium of Thanatephorus cucumeris. Phytopathology 57: 218-223.

797 Pine EM, Hibbett DS, Donoghue MJ, 1999. Phylogenetic relationships of cantharelloid and 798 clavarioid Homobasidiomycetes based on mitochondrial and nuclear rDNA sequences. $799 \quad$ Mycologia 91: 944-963. 
800 Polizzi G, Aiello D, Guarnaccia V, Panebianco A, Formica PT, 2011. First report of crown and root rot caused by Rhizoctonia solani AG-4 on banana passionflower (Passiflora mollissima) in Italy. Plant Disease 95: 1194

803 Prillieux E, Delacroix G, 1891. Hypochnus solani Nov. Sp. 7: 220-221.

804 Priyatmojo A, Yamauchi R, Kageyama K, Hyakumachi M, 2001. Grouping of binucleate Rhizoctonia anastomosis group D (AG-D) isolates into subgroups I and II based on whole-cell fatty acid compositions. Journal of Phytopathology 149: 421-426.

Rasmussen HN, 1995. Terrestrial orchids: from seed to mycotrophic plant. Cambridge University Press, Cambridge, U. K.

Reeb V, Lutzoni F, Roux C, 2004. Contribution of RPB2 to multilocus phylogenetic studies of the euascomycetes (Pezizomycotina, Fungi) with special emphasis on the lichen forming

813 Richter H, Schneider R, 1953. Untersuchungen zur morphologischen und biologischen differencierung von Rhizoctonia solani K. Phytopathologie Zeitshrift 20: 167-226.

815 Rinehart T, Copes W, Toda T, Cubeta MA, 2007. Genetic characterization of binucleate Rhizoctonia species causing web blight on azalea in Mississippi and Alabama. Plant Disease

817 91: 616-623.

818 Roberts P, 1999. Rhizoctonia-forming fungi. Royal Botanic Gardens, Kew.

819 Rolfs FM, 1903. Corticium vagum B. and C. var. solani Burt. A fruiting stage of Rhizoctonia $820 \quad$ solani. Science (NS) 18: 729.

821 Ronquist F, Huelsenbeck J, 2003. MrBayes 3: Bayesian phylogenetic inference under mixed models. Bioinformatics 19: 1572-1574. 
823 Royer-Carenzi M, Pontarotti P, Didier G, 2013. Choosing the best ancestral character state

824 reconstruction method. Mathematical Biosciences 242: 95-109.

825 Saksena HK, Vaartaja O, 1960. Description of new species of Rhizoctonia. Canadian Journal of

$826 \quad$ Botany 38: 931-943.

827 Salichos L, Rokas A, 2013. Inferring ancient divergences requires genes with strong

$828 \quad$ phylogenetic signals. Nature 497: 327-331.

829 Salichos L, Stamatakis A, Rokas A, 2014. Novel information theory-based measures for quantifying incongruence among phylogenetic trees. Molecular Biology and Evolution 31: 1261-1271.

832 Schoch CL, Sung GH, Lopez-Giraldez F, Townsend JP, Miadlikowska J, Hofstetter V, Robbertse B, Matheny PB, Kauff F, Wang Z, Gueidan C, Andrie RM, Trippe K, Ciufetti LM, Wynns A, Fraker E, Hodkinson BP, Bonito G, Groenewald JZ, Arzanlou M, de Hoog GS, Crous PW, Hewitt D, Pfister DH, Peterson K, Gryzenhout M, Wingfield MJ, Aptroot A, Suh SO, Blackwell M, Hillis DM, Griffith GW, Castlebury LA, Rossman AY, Lumbsch HT, Lucking R, Budel B, Rauhut A, Diederich P, Ertz D, Geiser DM, Hosaka K, Inderbitzin P, Kohlmeyer J, Volkmann-Kohlmeyer B, Mostert L, O'Donnell K, Sipman H, Rogers JD, Shoemaker RA, Sugiyama J, Summerbell RC, Untereiner W, Johnston PR, Stenroos S, Zuccaro A, Dyer PS, Crittenden PD, Cole MS, Hansen K, Trappe JM, Yahr R, Lutzoni F, Spatafora JW, 2009. The Ascomycota tree of life: a phylum-wide phylogeny clarifies the origin and evolution of fundamental reproductive and ecological traits. Systematic Biology 58: 224-239.

Schultz H, 1936. Vergleichende untersuchungen zur Okologie, Morphologie, und Systematik des "Vermehrungpilzes". Arbeiten ous der biologischen Reichsanstalt fur land und 
Forestwirtschat 22: 1-41.

847 Sharon M, Kuninaga S, Hyakumachi M, Sneh B, 2006. The advancing identification and classification of Rhizoctonia spp. using molecular and biotechnological methods compared with the classical anastomosis grouping. Mycoscience 47: 299-316.

Sharon M, Freeman S, Kuninaga S, Sneh B, 2007. Genetic diversity, anastomosis groups and virulence of Rhizoctonia spp. from strawberry. European Journal of Plant Pathology 117: $247-265$.

Sharon M, Kuninaga S, Hyakumachi M, Naito S, Sneh B, 2008. Classification of Rhizoctonia spp. using rDNA-ITS sequence analysis supports the genetic basis of the classical

Smith SA, Moore MJ, Brown JW, Yang Y, 2015. Analysis of phylogenomic datasets reveals conflict, concordance, and gene duplications with examples from animals and plants. BMC Evolutionary Biology 15: 150.

864 Stalpers JA, Andersen TF, 1996. A synopsis of the taxonomy of teleomorphs connected with

Sneh B, Burpee L, Ogoshi A, 1991. Identification of Rhizoctonia species. APS Press, St. Paul, Rhizoctonia s.l. In: Sneh B, Jabaji-Hare S, Neate S, Dijst G (eds), Rhizoctonia species: taxonomy, molecular biology, ecology, pathology and disease control. Kluwer Academic 
thousands of taxa and mixed models. Bioinformatics 22: 2688-2690.

870 Swofford DL, 2002. PAUP* Phylogenetic Analysis Using Parsimony (*and other methods),

871 version 4.0b10, Sinauer Associates, Sunderland, Massachusetts.

872 Talbot PHB, 1970. Taxonomy and nomenclature of the perfect state. In: Parmeter JRJ (ed), Rhizoctonia solani: Biology and Pathology. University of California Press, Berkeley, pp 20-31.

875 Taylor DL, McCormick MK, 2008. Internal transcribed spacer primers and sequences for improved characterization of basidiomycetous orchid mycorrhizas. New Phytologist 177:

Toda T, Hyakumachi M, Suga H, Kageyama K, Tanaka A, Tani T, 1999. Differentiation of Rhizoctonia AG-D isolates from turfgrass into subgroups I and II based on rDNA and RAPD analyses. European Journal of Plant Pathology 105: 835-846.

Vilgalys R, Cubeta MA, 1994. Molecular systematics and population biology of Rhizoctonia.

Veldre V, Abarenkov K, Bahram M, Martos F, Selosse M-A, Tamm H, Kõljalg U, Tedersoo L, 2013. Evolution of nutritional modes of Ceratobasidiaceae (Cantharellales, Basidiomycota) as revealed from publicly available ITS sequences. Fungal Ecology $\mathbf{6}$ : 256-268. Annual Review of Phytopathology 32: 135-155.

Vilgalys R, Hester M, 1990. Rapid genetic identification and mapping of enzymatically amplified ribosomal DNA from several Cryptococcus species. Journal of Bacteriology 172: $4238-4246$.

Warcup JH, Talbot PHB, 1971. Perfect states of Rhizoctonias associated with orchids II. New 
892 Warcup JH, Talbot PHB, 1980. Perfect states of Rhizoctonias associated with orchids III. New

893 Phytologist 86: 267-272.

894 Warcup JH, 1985. Rhizanthella gardneri (Orchidaceae), its Rhizoctonia endophyte and close association with Melaleuca uncinata (Myrtaceae) in western Australia. New Phytologist 99: $273-280$.

897 Warcup JH, 1991. The Rhizoctonia endophytes of Rhizanthella (Orchidaceae). Mycological Ressearch 95: 656-641.

Wiens JJ, 2006. Missing data and the design of phylogenetic analyses. Biomedical Informatics

$900 \quad 39: 34-42$.

901 Windels CE, Kuzina RA, Call J, 1997. Characterization and phathogenecity of Thanatephorus 902 cucumeris from sugarbeet in Minnesota. Plant Disease 81: 245-249.

903 White TJ, Bruns T, Lee S, Taylor J. 1990. Amplification and direct sequencing of fungal ribosomal RNA genes for phylogenetics In: Innis MA, Gelfand DH, Sninsky JJ, White TJ (eds), PCR Protocols a guide to methods and applications. Academic Press, San Diego,

907 Wielstra B, Arntzen JW, Gaag KJ van der, Pabijan M, Babik W, 2014. Data concatenation, pp 315-322. Bayesian concordance and coalescent-based analyses of the species tree for the rapid

Woodhall JW, Lees AK, Edwards SG, Jenkinson P, 2007. Characterization of Rhizoctonia solani radiation of Triturus newts. PLOS ONE 9(10): e111011.

913 Yagame T, Yamato M, Suzuki A, Iwase K, 2008. Ceratobasidiaceae mycorrhizal fungi isolated from nonphotosynthetic orchid Chamaegastrodia sikokiana. Mycorrhiza 18: 97-101. 
915 Yagame T, Orihara T, Selosse M-A, Yamato M, Iwase K, 2012. Mixotrophy of Platanthera

916 minor, an orchid associated with ectomycorrhiza-forming Ceratobasidiaceae fungi. New

917 Phytologist 193: 178-187.

918 Yanar Y, Yllmaz G, Cesmeli I, Coskun S, 2005. Characterization of Rhizoctonia solani isolates

919 from potatoes in Turkey and screening potato cultivars for resistance to AG-3 isolates.

$920 \quad$ Phytoparasitica 33: 370-376.

921 Yokoyama K, Ogoshi A, 1986. Studies on hyphal anastomosis of Rhizoctonia solani IV.

922 Observation of imperfect fusion by light and electron microscopy. Transactions of the

923 Mycological Society of Japan 27: 399-413.

924 Zwickl D, 2006. Genetic algorithm approaches for the phylogenetic analysis of large biological

925 sequence datasets under the maximum likelihood criterion [doctoral dissertation],

926 University of Texas at Austin, Austin, Texas. 
1 Table 1 - Anastomosis group (AG) affinity, plant host, geographic origin, and GenBank accession numbers of Rhizoctonia fungi used

2 in this study.

\begin{tabular}{|c|c|c|c|c|c|c|c|c|c|}
\hline \multirow{2}{*}{ Isolate } & \multirow{2}{*}{$\mathrm{AG}$} & \multirow{2}{*}{ Host } & \multirow{2}{*}{$\begin{array}{c}\text { Geographic } \\
\text { origin }\end{array}$} & \multirow{3}{*}{$\begin{array}{l}\quad \text { Other name(s) } \\
\text { R. solani, } \\
\text { Thanatephorus } \\
\text { pendulus, } \\
\text { Aquathanatephorus } \\
\text { pendulus }\end{array}$} & \multicolumn{5}{|c|}{ GenBank accession number } \\
\hline & & & & & \multicolumn{2}{|c|}{ ITS-LSU } & \multirow{2}{*}{$r p b 2$} & \multirow{2}{*}{$\begin{array}{c}\text { tefl } \alpha \\
\text { DQ301660 }\end{array}$} & \multirow{2}{*}{$\begin{array}{c}\text { atp6 } \\
\text { DQ301596 }\end{array}$} \\
\hline CBS 700.82 & AG-1-IA & $\begin{array}{l}\text { Eichhornia } \\
\text { crassipes }\end{array}$ & Panama & & KP171634 & - & & & \\
\hline CBS 206.84 & AG-1-IB & $\begin{array}{l}\text { Phaseolus } \\
\text { vulgaris }\end{array}$ & Japan & \multirow{4}{*}{ T. sasakii, R. solani } & DQ279038 & KP171642 & DQ301747 & DQ301680 & DQ301616 \\
\hline CBS 140.82 & AG-1-IC & Glycine max & Canada & & DQ279062 & - & DQ301730 & DQ301677 & DQ301613 \\
\hline CBS 207.84 & AG-1-IC & $\begin{array}{l}\text { Phaseolus } \\
\text { vulgaris }\end{array}$ & Japan & & DQ278991 & - & DQ301748 & DQ301681 & DQ301617 \\
\hline CBS 523.96 & AG-1-IC & Pinus sp. & Canada & & DQ279032 & - & DQ301751 & DQ301685 & DQ301621 \\
\hline SJ07 & $\begin{array}{l}\text { AG-2-2 } \\
\text { IIIB }\end{array}$ & Glycine max & Brazil & \multirow{2}{*}{$\begin{array}{l}\text { Thanatephorus } \\
\text { cucumeris }\end{array}$} & AY270015 & - & DQ301755 & DQ301689 & DQ301625 \\
\hline SA1-1 & AG-2-2 IV & Glycine max & Japan & & KP171635 & KP171643 & DQ301734 & DQ301666 & DQ301602 \\
\hline CBS 208.84 & AG-2-1 & $\begin{array}{l}\text { Linum } \\
\text { usitatissimum }\end{array}$ & Japan & R. solani & EU244841 & - & DQ301749 & DQ301682 & DQ301618 \\
\hline Rhs1AP* & AG-3 PT & $\begin{array}{l}\text { Solanum } \\
\text { tuberosum }\end{array}$ & USA, Maine & \multirow{2}{*}{ T. cucumeris } & KP171636 & KP171644 & DQ301735 & DQ301667 & DQ301603 \\
\hline CBS 200.25 & AG-3 PT & $\begin{array}{l}\text { Solanum } \\
\text { tuberosum }\end{array}$ & NA & & DQ278994 & KP171645 & DQ301746 & DQ301679 & DQ301615 \\
\hline SJ02 & AG-4 HGI & Glycine max & Puerto Rico & \multirow{3}{*}{ T. praticola } & AY270003 & - & DQ301754 & DQ301688 & DQ301624 \\
\hline AH-1 & AG-4 HGI & Arachis hypogea & Japan & & AY154307 & - & DQ301736 & DQ301668 & DQ301604 \\
\hline 187-Rs & $\begin{array}{l}\text { AG-4 } \\
\text { HGIII } \\
\end{array}$ & Arachis hypogea & $\begin{array}{c}\text { USA, } \\
\text { Georgia }\end{array}$ & & AY154309 & - & DQ301738 & DQ301670 & DQ301606 \\
\hline Rh-165 & AG-4 HGII & Beta vulgaris & Japan & T. praticola & AB000033 & - & DQ301737 & DQ301669 & DQ301605 \\
\hline GM 10 & AG-5 & Glycine max & Japan & \multirow{3}{*}{ Rhizoctonia sp. } & KP171637 & KP171646 & DQ301739 & DQ301671 & DQ301607 \\
\hline OHT-1-1 & AG-6 HGI & Soil & Japan & & AF153779 & - & DQ301740 & DQ301672 & DQ301608 \\
\hline 76Rs & AG-7 & Soil & Japan & & AF354096 & AF354096 & DQ301741 & DQ301673 & DQ301609 \\
\hline CBS 101782 & AG-8 & Triticum aestivum & Australia & Thanatephorus sp. & DQ279008 & KP171647 & DQ301744 & DQ301676 & DQ301612 \\
\hline $\mathrm{S}-21$ & AG-9 & Soil & USA, Alaska & \multirow[b]{2}{*}{$R$. solani } & KP171638 & - & DQ301742 & DQ301674 & DQ301610 \\
\hline CBS 970.96 & AG-9 & $\begin{array}{l}\text { Solanum } \\
\text { tuberosum }\end{array}$ & USA, Alaska & & DQ279005 & KP171648 & DQ301752 & DQ301686 & DQ301622 \\
\hline
\end{tabular}




\begin{tabular}{|c|c|c|c|c|c|c|c|c|c|}
\hline CBS 346.84 & AG-10 & Spinacia oleracea & $\begin{array}{l}\text { The } \\
\text { Netherlands }\end{array}$ & R. solani & DQ278947 & - & DQ301750 & DQ301684 & DQ301588 \\
\hline C-538 & AG-A & $\begin{array}{l}\text { Solanum } \\
\text { tuberosum }\end{array}$ & Japan & $\begin{array}{l}\text { C. cornigerum, } \\
\text { C. raminicola, } \\
\text { CAG } 2\end{array}$ & DQ279052 & - & DQ301695 & DQ301631 & DQ301565 \\
\hline $\mathrm{C}-484$ & $\mathrm{AG}-\mathrm{Ba}$ & Oryzae sativae & Japan & Ceratobasidium sp. & AB196641 & KP171649 & DQ301696 & DQ301632 & DQ301566 \\
\hline CBS 569.83 & AG-Bb & $\begin{array}{l}\text { Trichoglottis } \\
\text { australiensis }\end{array}$ & Australia & $\begin{array}{l}\text { Ceratobasidium } \\
\text { globisporum }\end{array}$ & DQ278942 & - & DQ301723 & DQ301644 & DQ301592 \\
\hline SIR-2 & AG-A & Ipomoea batatis & Japan & C. cornigerum & AF354091 & AF354091 & DQ301697 & DQ301633 & DQ301567 \\
\hline CBS 132.82 & AG-D & Festuca sp. & USA & \multirow{3}{*}{$\begin{array}{l}\text { C. cornigerum, } C \text {. } \\
\text { cereale, } C . \\
\text { graminearum, } C . \\
\text { oryzae-sativae, } R \text {. } \\
\text { cerealis, CAG } 1\end{array}$} & DQ278930 & - & DQ301707 & DQ301645 & DQ301576 \\
\hline CBS 223.51 & AG-D & Unknown & Japan & & DQ278939 & - & - & DQ301655 & DQ301586 \\
\hline CBS 438.80 & AG-D & Juncus sp. & Japan & & KP171639 & KP171650 & DQ301719 & DQ301656 & DQ301589 \\
\hline F-18 & AG-E & $\begin{array}{l}\text { Linum } \\
\text { usitatissimum }\end{array}$ & Japan & $\begin{array}{l}\text { Ceratobasidium } \\
\text { sp., CAG } 6\end{array}$ & DQ279013 & - & DQ301699 & DQ301635 & DQ301569 \\
\hline CBS 137.82 & AG-E & $\begin{array}{l}\text { Conyza } \\
\text { canadensis }\end{array}$ & USA & $\begin{array}{l}\text { Ceratobasidium } \\
\text { cornigerum, CAG6 }\end{array}$ & DQ278934 & KP171651 & DQ301711 & DQ301649 & DQ301580 \\
\hline AH-6 & AG-F & Arachis hypogea & Japan & $\begin{array}{l}\text { Ceratobasidium } \\
\text { sp., CAG } 4\end{array}$ & DQ279014 & - & DQ301700 & - & - \\
\hline $\mathrm{AH}-9$ & AG-G & Arachis hypogea & Japan & Ceratobasidium sp. & AB196646 & KP171652 & DQ301701 & DQ301636 & DQ301570 \\
\hline $\mathrm{C}-158$ & AG-P & Camillia sinensis & Japan & Ceratobasidium sp. & DQ279015 & - & DQ301705 & DQ301640 & DQ301573 \\
\hline C-620 & AG-Q & Cynodon dactylon & Japan & Ceratobasidium sp. & AF354095 & AF354095 & KP171657 & DQ301641 & DQ301574 \\
\hline CBS 136.82 & AG-R & Taxus sp. & USA & $\begin{array}{l}\text { C. cornigerum, } \\
\text { CAG } 5\end{array}$ & DQ278933 & KP171653 & DQ301710 & DQ301648 & DQ301579 \\
\hline CBS 139.82 & AG-S & Pittosporum sp. & USA & $\begin{array}{l}\text { C. cornigerum, } \\
\text { CAG } 7\end{array}$ & DQ278936 & - & DQ301713 & DQ301650 & DQ301581 \\
\hline CBS 135.82 & AG-U & Juniperus sp. & USA & $\begin{array}{l}\text { C. cornigerum, } \\
\text { C. raminicola, } \\
\text { CAG } 3\end{array}$ & DQ278932 & - & DQ301709 & DQ301647 & DQ301578 \\
\hline CBS 476.82 & ND & Glycine max & USA & $\begin{array}{l}\text { C. cornigerum, } \\
\text { CAG } 4\end{array}$ & DQ278941 & KP171654 & DQ301720 & DQ301643 & - \\
\hline CBS 293.31 & ND & Gossypium sp. & Turkey & Thanatephorus sp. & DQ278959 & - & DQ301729 & DQ301683 & DQ301619 \\
\hline CBS 148.54 & ND & Unknown & France & C. cornigerum & DQ278937 & KP171656 & DQ301714 & DQ301651 & - \\
\hline CBS 570.83 & ND & $\begin{array}{l}\text { Sarcochilus } \\
\text { dilatatus }\end{array}$ & Australia & $\begin{array}{l}\text { C. } \text { cornigerum, } \\
\text { C. papillatum } \\
\end{array}$ & AJ427401 & - & DQ301724 & - & - \\
\hline CBS 154.35 & ND & Coffea sp. & India & $\begin{array}{l}\text { Ceratobasidium } \\
\text { noxium, Corticium } \\
\text { koleroga }\end{array}$ & DQ278938 & - & DQ301715 & DQ301653 & DQ301584 \\
\hline
\end{tabular}




\begin{tabular}{|c|c|c|c|c|c|c|c|c|c|}
\hline CBS 571.83 & ND & $\begin{array}{l}\text { Pomatocalpa } \\
\text { macphersonii }\end{array}$ & Australia & $\begin{array}{l}\text { Ceratobasidium } \\
\text { sphaerosporum }\end{array}$ & DQ278943 & - & DQ301725 & DQ301658 & DQ301594 \\
\hline DAOM 138188 & ND & Pinus banksiana & $\begin{array}{l}\text { Canada, } \\
\text { Saskatchewan }\end{array}$ & $\begin{array}{l}\text { Rhizoctonia } \\
\text { endophytica, } \\
\text { Ceratobasidium } \\
\text { sp., C. cornigerum }\end{array}$ & KP171640 & KP171655 & KP171658 & - & - \\
\hline AFTOL ID 611 & ND & & & $\begin{array}{l}\text { Thanatephorus } \\
\text { (synonym } \\
\text { Uthatobasidium) } \\
\text { fusisporum }\end{array}$ & DQ398957 & AF518664 & DQ381842 & - & - \\
\hline $\begin{array}{l}\text { AFTOL ID } 610 \\
\text { DAOM } 17641\end{array}$ & ND & Populus sp. & $\begin{array}{l}\text { Canada, } \\
\text { Ontario }\end{array}$ & $\begin{array}{l}\text { Tulasnella } \\
\text { pruinosa }\end{array}$ & DQ457642 & - & DQ381839 & DQ061274 & - \\
\hline GEL2348 & ND & & Germany & $\begin{array}{l}\text { Botryobasidium } \\
\text { simile }\end{array}$ & KP171641 & DQ898730 & DQ898770 & - & - \\
\hline AFTOL ID 667 & ND & & & Clavulina sp. & DQ202266 & AY745694 & DQ366286 & DQ028589 & DQ120947 \\
\hline AFTOL ID 607 & ND & & & $\begin{array}{l}\text { Cantharellus } \\
\text { cibarius }\end{array}$ & DQ200926 & - & DQ366285 & DQ059050 & - \\
\hline AFTOL ID 471 & ND & & & $\begin{array}{l}\text { Hydnum } \\
\text { albomagnum }\end{array}$ & DQ218305 & AY700199 & DQ234553 & DQ234568 & - \\
\hline
\end{tabular}

$3 \mathrm{ND}=$ not determined

$4 \quad-=$ no sequence data

5 Strain Rhs1AP denoted by the asterisk represents a strain used in this study for which the genome sequence is available (Cubeta et al. 6 2014) 
Table 2. Primers sequence and PCR conditions applied for each of the genes employed to analyze relationships among Rhizoctonia fungi. An asterisk (*) indicates 35 cycles for PCR. All other PCRs were 30 cycles.

\begin{tabular}{|c|c|c|c|c|}
\hline \multirow[b]{2}{*}{ Gene } & \multirow[b]{2}{*}{ Primer name } & \multirow[b]{2}{*}{ Reference } & \multirow[b]{2}{*}{ Sequence $\left(5^{\prime}-3^{\prime}\right)$} & Cycle conditions \\
\hline & & & & $\begin{array}{l}\text { annealing/ } \\
\text { extension }\end{array}$ \\
\hline \multirow{4}{*}{$r p b 2$} & bRPB2-6F & \multirow{4}{*}{$\begin{array}{l}\text { Matheny } \\
2005 \\
\text { Reeb et al. } \\
2004 \\
\text { Liu et al. } \\
1999\end{array}$} & TGGGGYATGGNTTGYCCYGC & $60^{\circ} \mathrm{C}, 1 \mathrm{~min}$ \\
\hline & bRPB2-7.1R & & CCCATRGCYTGYTTMCCCAT & $72{ }^{\circ} \mathrm{C}, 2 \mathrm{~min}$ \\
\hline & RPB2-980F & & TGYCCIGCIGARACICCHGARGG & $52^{\circ} \mathrm{C}, 1 \mathrm{~min}$ \\
\hline & fRPB2-7cR & & CCCATRGCTTGYTTRCCCAT & $72{ }^{\circ} \mathrm{C}, 2 \mathrm{~min}$ \\
\hline \multirow{2}{*}{ tefl } & TEF1-F & \multirow{2}{*}{$\begin{array}{l}\text { Litvintseva } \\
\text { et al. } 2006\end{array}$} & AATCGTCAAGGAGACCAACG & $60^{\circ} \mathrm{C}, 1 \mathrm{~min}$ \\
\hline & TEF1-R & & CGTCACCAGACTTGACGAAC & $72{ }^{\circ} \mathrm{C}, 2 \mathrm{~min}$ \\
\hline \multirow[b]{2}{*}{ atp6 } & ATP61 & \multirow{2}{*}{$\begin{array}{l}\text { Kretzer and } \\
\text { Bruns } 1999\end{array}$} & ATTAATTSWCCWTTAGAWCAATT & touch down: $*$ \\
\hline & ATP62 & & $\begin{array}{l}\text { TAATTCTANWGCATCTTTAATRT } \\
\text { A }\end{array}$ & $\begin{array}{l}37^{\circ} \mathrm{C}, 55 \mathrm{sec} \\
72^{\circ} \mathrm{C}, 1 \mathrm{~min} \\
\text { then } \\
45^{\circ} \mathrm{C}, 55 \mathrm{sec} \\
72^{\circ} \mathrm{C}, 1 \mathrm{~min}(+4 \\
\text { sec/cycle })\end{array}$ \\
\hline \multirow{2}{*}{ ITS } & ITS4 & \multirow{2}{*}{$\begin{array}{l}\text { White et al. } \\
1990\end{array}$} & TCCTCCGCTTATTGATATGC & $55^{\circ} \mathrm{C}, 1 \mathrm{~min}$ \\
\hline & ITS5 & & GGAAGTAAAAGTCGTAACAAGG & $72^{\circ} \mathrm{C}, 2 \mathrm{~min}$ \\
\hline \multirow[b]{2}{*}{ LSU } & LROR & \multirow{2}{*}{$\begin{array}{l}\text { Vilgalys } \\
\text { and Hester } \\
1990\end{array}$} & GTACCCGCTGAACTTAAGC & $51^{\circ} \mathrm{C}, 45 \mathrm{sec}$ \\
\hline & LR5 & & ATCCTGAGGGAAACTTC & $72^{\circ} \mathrm{C}, 2.5 \mathrm{~min}$ \\
\hline
\end{tabular}


Table 3 - Sequence data, their properties, and estimated models of sequence evolution for each locus and combined (Figs 2 and Supplementary S1)

\begin{tabular}{|c|c|c|c|c|c|c|c|c|}
\hline \multirow[b]{2}{*}{ Locus } & \multirow{2}{*}{$\begin{array}{l}\text { No. of } \\
\text { isolates in } \\
\text { matrix }\end{array}$} & \multirow{2}{*}{$\begin{array}{l}\text { Length } \\
\text { alignment }\end{array}$} & \multicolumn{4}{|c|}{ MP analyses } & \multicolumn{2}{|c|}{ ML analyses } \\
\hline & & & $\begin{array}{c}\text { Informative } \\
\text { characters }\end{array}$ & No. of trees & Length & Indices & Best-fit model & -ln scores \\
\hline ITS-LSU & 50 & 1462 & 418 & 2 & 1567 & $\begin{array}{l}\mathrm{CI}=0.459 \\
\mathrm{RI}=0.579 \\
\mathrm{RC}=0.266\end{array}$ & $\mathrm{TIM} 2+\mathrm{G}$ & 10466.4260 \\
\hline$r p b 2$ & 49 & 674 & 367 & 18 & 2016 & $\begin{array}{l}\mathrm{CI}=0.330 \\
\mathrm{RI}=0.563 \\
\mathrm{RC}=0.186\end{array}$ & $\mathrm{TVM}+\mathrm{G}$ & 8862.3926 \\
\hline tefl & 45 & 514 & 372 & 71 & 1371 & $\begin{array}{l}\mathrm{CI}=0.468 \\
\mathrm{RI}=0.682 \\
\mathrm{RC}=0.319\end{array}$ & $\operatorname{TrN}+\mathrm{G}$ & 6427.2248 \\
\hline atp6 & 40 & 668 & 182 & 48 & 630 & $\begin{array}{l}\mathrm{CI}=0.448 \\
\mathrm{RI}=0.763 \\
\mathrm{RC}=0.341\end{array}$ & TPM3uf+G & 4515.7805 \\
\hline Combined & 50 & 3318 & 1339 & 2 & 6079 & $\begin{array}{l}\mathrm{CI}=0.380 \\
\mathrm{RI}=0.575 \\
\mathrm{RC}=0.218\end{array}$ & TIM3+I+G & 33315.3131 \\
\hline
\end{tabular}


Fig 1 - Phylogenetic hypothesis of the Cantharellales based on nucleotide sequences of rpb2. The tree is a Bayesian 50\% majority-rule consensus tree and produced from a data set of 165 sequences and 487 nucleotide characters. Only support values for main clades and the thanatephoroid clade within the Ceratobasidiaceae are shown. Posterior probabilities are indicated to the left, and ML bootstrap values to the right. Taxa marked in bold were those used in multi-locus analyses.

Fig 2 - Hypotheses of inferred relationships of Rhizoctonia fungi obtained with: i) Maximum Parsimony (MP), ii) Maximum Likelihood (ML) and iii) Bayesian Phylogenetic Inference (BPI) for concatenated data set of four genomic regions (ITSLSU, rpb2, tef1 and atp6). Taxa shaded in grey are the members of the family Ceratobasidiaceae. Nodes that collapsed in the strict consensus tree are marked with an asterisk. Scale bar for ML and BPI represents nucleotide substitution per site, and for MP the number of steps. Values for support above $80 \%$ for two of three metrics (MP bootstrap, ML bootstrap or PP) are shown as thick branches.

Fig 3 - Phylogenetic relationships of Rhizoctonia fungi based on parsimony analysis of the concatenated data set of four genomic regions (ITS-LSU, rpb2, tef1 and atp6). Values for support above $80 \%$ for at least two metrics (MP bootstrap/ML bootstrap/PP) are reported along the branches. Roman numerals (I-X) indicate supported clades (>80\%) with all three metrics. Circles below branches indicate concordance factors above 0.5 .

Fig 4 - ML phylogeny of the Cantharellales showing genomic support. Left tree shows internode certainty (IC and ICA values respectively). Right tree shows the number of 
genomic regions (ITS-LSU, rpb2, tef1, atp6) that support a specific clade. Numbers at the left are concordant genes, at right those that are in conflict. 


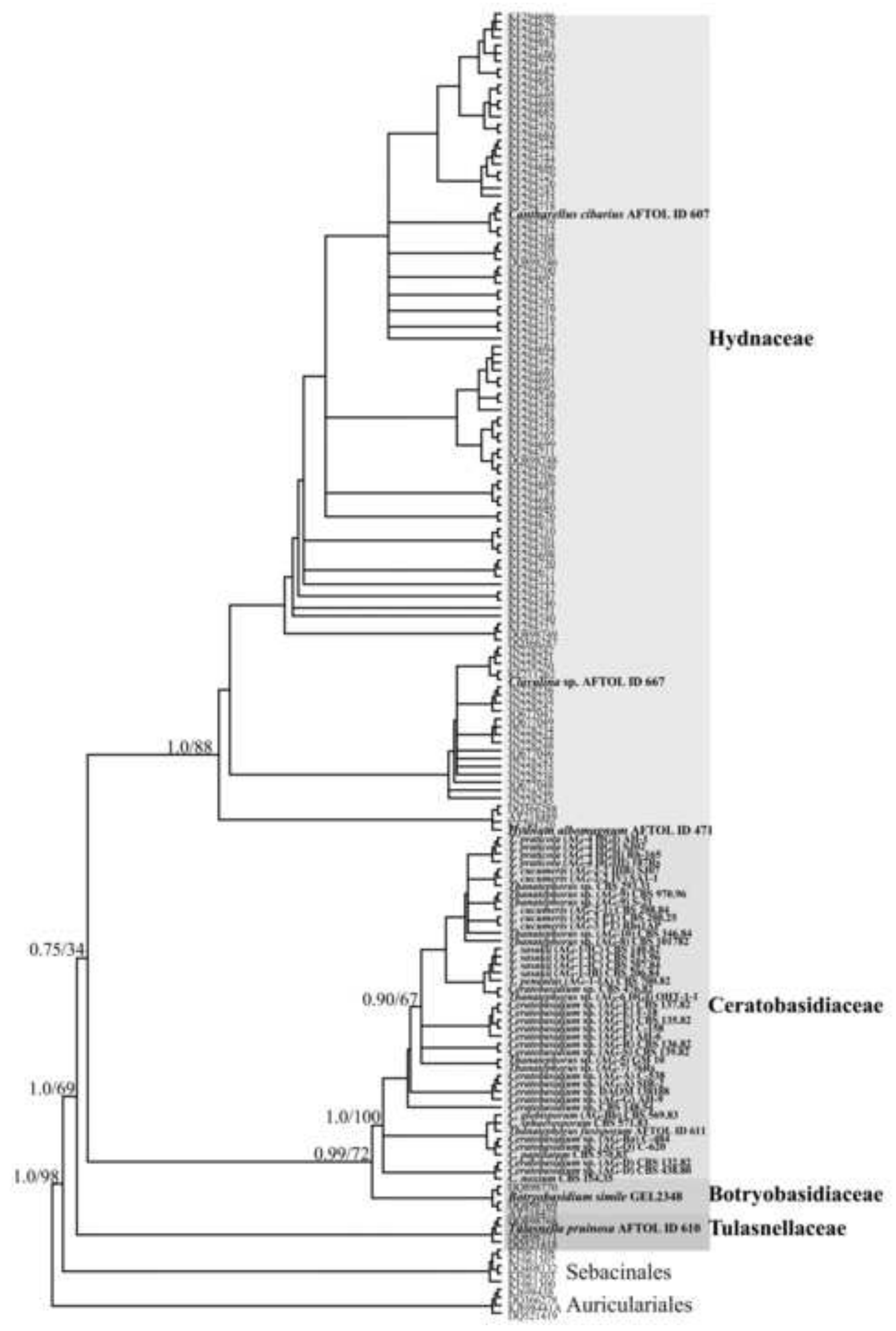

Figure(s)

\section{Hydnaceae}

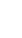

Tulys

Ceratobasidiaceac e idiaceae 
i

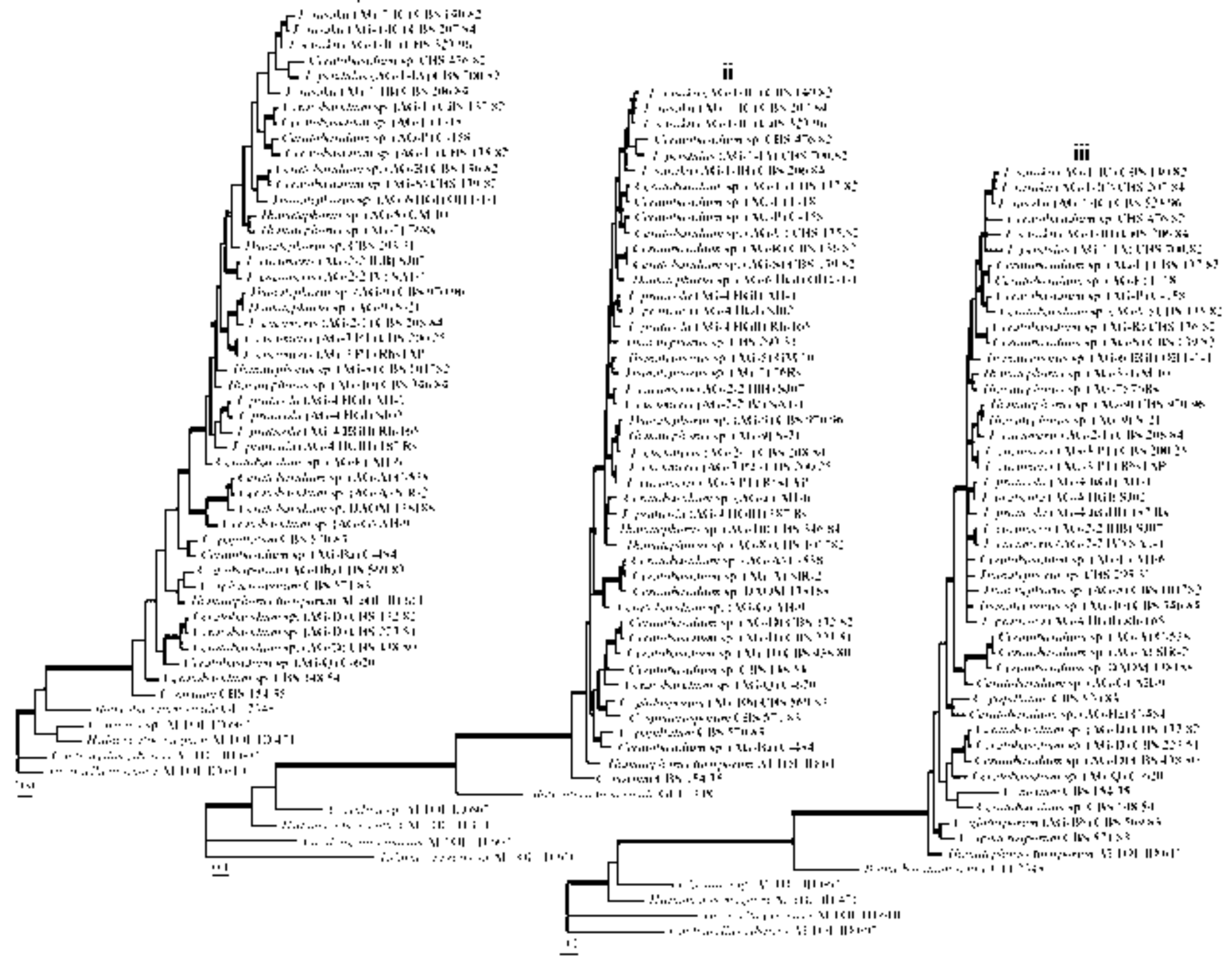




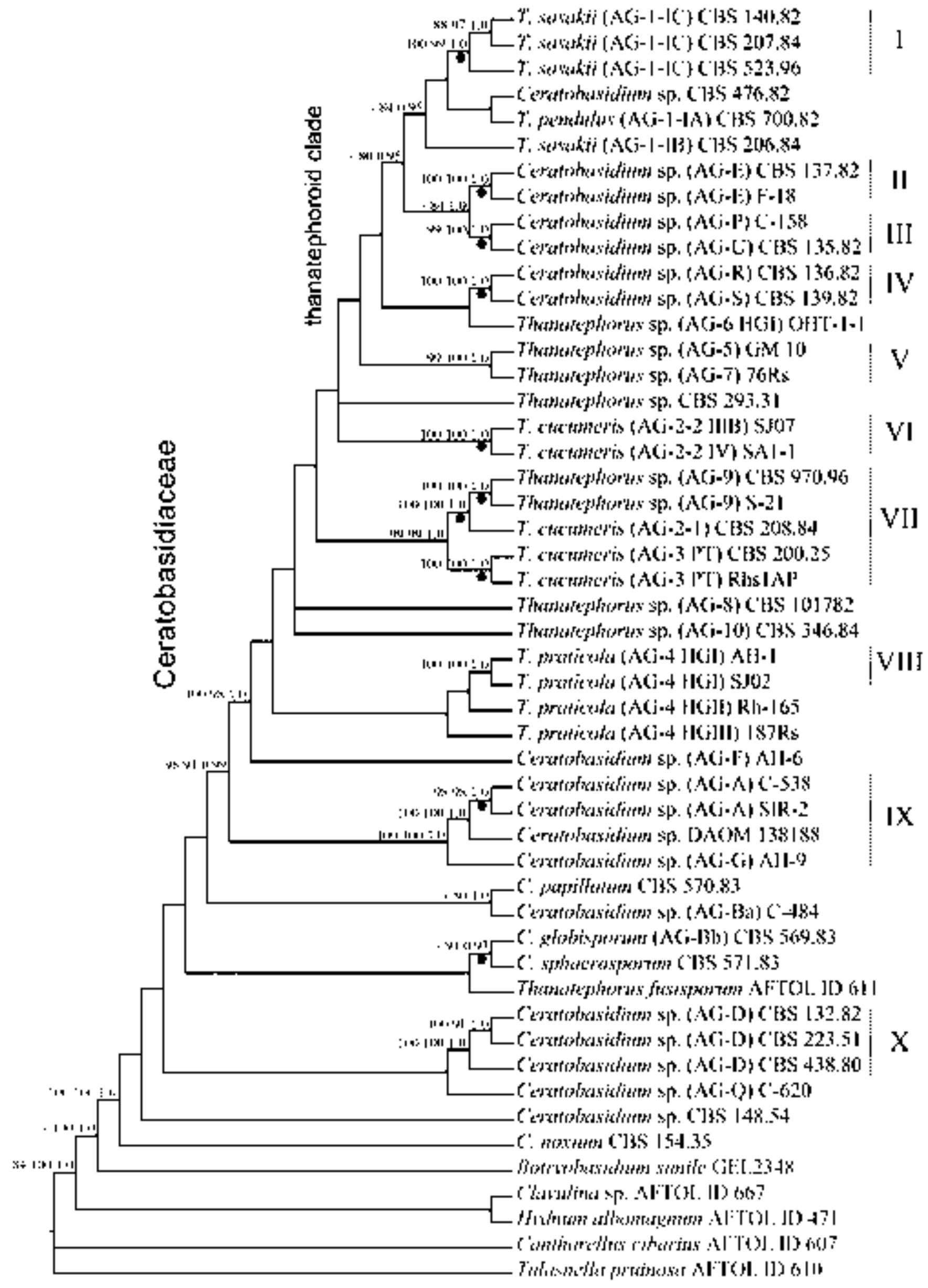




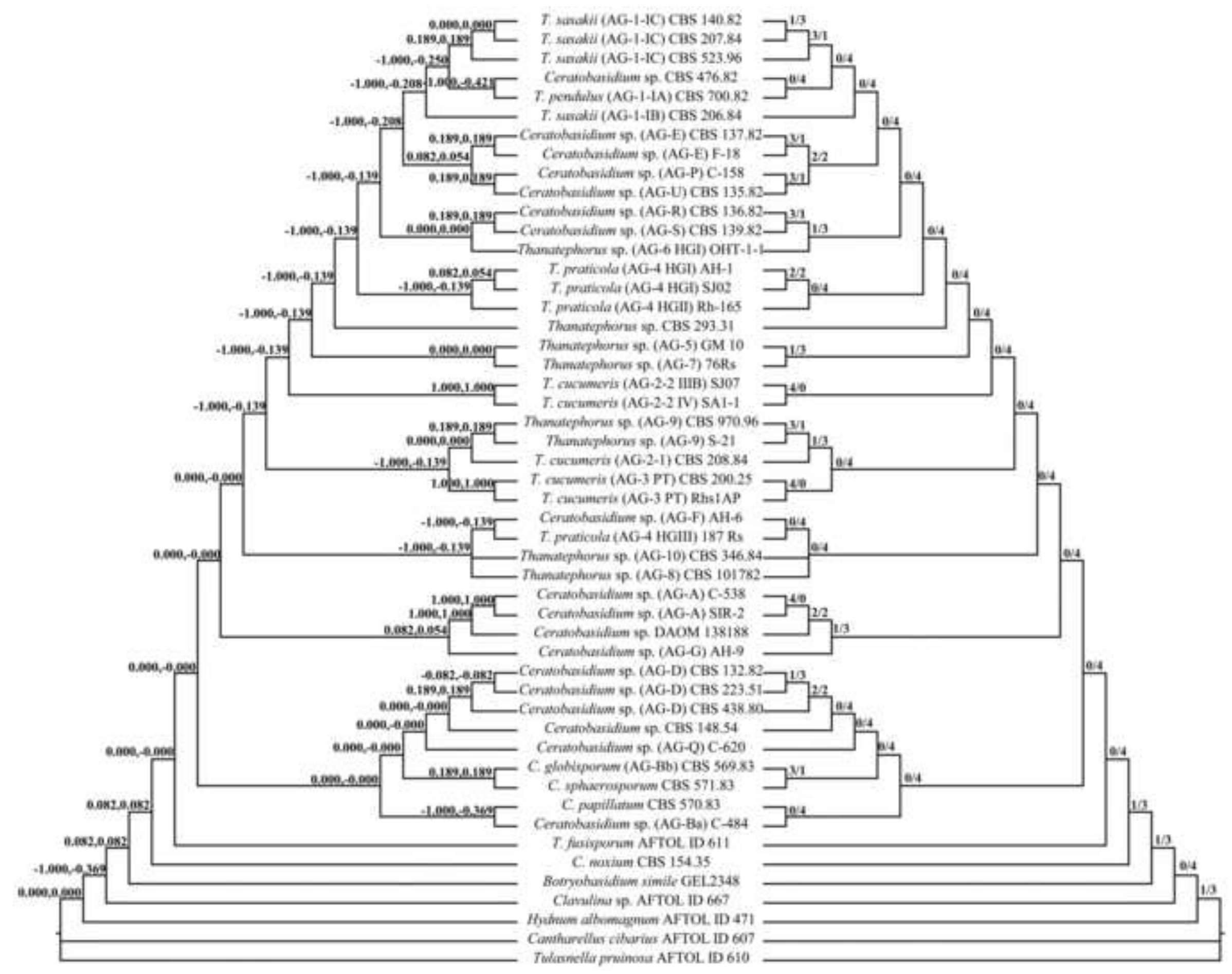

